\title{
Investigation of Mild Steel Corrosion in the Cement Production Associated with the Usage of Secondary Fuels
}

\author{
Michael Thieme, ${ }^{1}$ Ute Bergmann $\mathbb{D}^{1},{ }^{1}$ Anja Kiesewetter, ${ }^{1}$ Tobias Wehry, ${ }^{2}$ Kay Potzger, ${ }^{3}$ \\ Arkadiusz Zarzycki, ${ }^{4}$ Marta Marszalek, ${ }^{4}$ and Hartmut Worch ${ }^{1}$ \\ ${ }^{1}$ Institute of Materials Science, University of Technology Dresden, 01062 Dresden, Germany \\ ${ }^{2}$ Opterra Zement GmbH, Plant Karsdorf, 06638 Karsdorf, Germany \\ ${ }^{3}$ Institute of Ion Beam Physics and Materials Research, Helmholtz-Zentrum Dresden-Rossendorf (HZDR, Bautzner Landstrasse 400, \\ 01328 Dresden, Germany \\ ${ }^{4}$ The Henryk Niewodniczanski Institute of Nuclear Physics (IFJ PAN), Polish Academy of Sciences, 31-342 Kraków, Poland
}

Correspondence should be addressed to Ute Bergmann; ute.bergmann@tu-dresden.de

Received 7 April 2020; Revised 24 July 2020; Accepted 25 August 2020; Published 18 September 2020

Academic Editor: Dongyang Y. Li

Copyright (C) 2020 Michael Thieme et al. This is an open access article distributed under the Creative Commons Attribution License, which permits unrestricted use, distribution, and reproduction in any medium, provided the original work is properly cited.

\begin{abstract}
The present work deals with the corrosion of mild steel (1.0037) used as the outer construction material of the preheater of a modern industrial cement production facility. The facility uses secondary fuels, which introduce considerable amounts of corrosive species. The situation at the examination sites in the preheater zone is tracked over a period of two years including operation and shut-down periods. The investigation is focused on (i) the acquisition of the underlying physicochemical conditions, such as moisture, temperature, and contamination data at the examination site of the preheater, (ii) the multianalytical identification of the formed corrosion products using scanning electron microscopy combined with energydispersive X-ray analysis, infrared spectrometry, Raman spectrometry, X-ray diffractometry, and Mö $\beta$ bauer spectrometry, and (iii) voltammetric and EIS laboratory investigations using model solutions. It was evidenced that corrosion takes place at a temperature level of about $100^{\circ} \mathrm{C}$ in the presence of moisture and oxygen as well as chloride ion as a consequence of the usage of secondary fuels. Typical hot-gas corrosion could be excluded under the current conditions. Appearance, structure, and nature of the corrosion products were found to be not mainly dependent on the varied length of exposure, but on the conditions of the hosting preheater intake. In addition to different $\mathrm{FeOOH}$ phases and hematite, magnetite was found, dependent on the oxygen concentration in the process gas. The decisive role of oxygen as key factor for the corrosion rate was electrochemically confirmed.
\end{abstract}

\section{Introduction}

The cement production is inevitably connected with two critical phenomena, which shall be addressed at first: energy and fuel consumption and the release of carbon dioxide as one of the green-house gases. As for the latter, the production of one ton of clinker from appropriate amounts of lime, sand, clay, and iron-containing material causes the emission of 0.65-0.90t of carbon dioxide due to fuel combustion and the primary decomposition of lime $\mathrm{CaCO}_{3}$ into quick lime $\mathrm{CaO}$. Correspondingly, the cement industry accounts for about $7 \%$ of the total global $\mathrm{CO}_{2}$ emission $[1,2]$.

In terms of the consumption of energy and fuels, alternative energy sources, the so-called secondary fuels (SFs), have been increasingly deployed worldwide for about three decades in order to save fossil fuels, to diminish the greenhouse gas emission, and, at the same time, to manage waste problems [3]. A detailed report of the German Umweltbundesamt sums up a substituted energy equivalent of $40 \mathrm{PJ}$ alone for the German cement industry in the year 2004 [4]. This corresponds to a fraction of more than $42 \%$ of the total thermal energy consumption in the cement production sector. No doubt, these figures will have considerably increased during the recent years. A Chinese paper stresses that even $91 \%$ of coal could be replaced by cofiring oil sludge [5]. Altogether, 16 different types of industrial, agricultural, and urban refuse-derived SFs are discerned by ref. [4], representing different consistency and degree of preprocessing. 
Old tires, waste plastics, and animal waste products amount to the largest fractions [6].

The distinctly deviating chemical composition of the SFs in comparison to traditional fuels introduces a diversity of critical chemical elements, such as alkalis, chlorine, and sulphur, into the cement production facility. These elevated concentration levels may affect the cement product quality, environmental pollution [7], and, last not least, the corrosion behaviour of the incorporated construction materials, i.e., in the interior of the rotary kiln [8]. As for the mechanism, the high-contamination conditions will lead to the formation of volatile alkali compounds, mixed oxides, and metal chlorides, which spread throughout the total system [8-10]. As one of the possible pathways, these salts may undergo desublimation on sufficiently colder (metal) surfaces. Consequently, melts and substances with hygroscopic and deliquescent properties are formed and a high corrosion potential arises. All in all, the situation will be similar as described for other high-contamination, high-temperature facilities, and technologies [11-15].

For the production of clinker, it should be taken into account that corrosion of the steel mantle can principally occur under the regular operation conditions, dependent on the actual position in the facility, as well as during the planned shut-down period in wintertime, when dew-point undershooting for water may happen at the cold steel cladding [8].

This paper focuses on the aspects of corrosion and, hence, lifetime of unalloyed steel components in the region of the preheater, which is run on a considerably lower temperature level than in the rotary kiln. As for its function, the milled raw materials are stepwise heated up by the process gases in counter current, before they will reach the rotary kiln with its special pyroprocessing. The specific examination sites within the preheater are marked in Figure 1. Both preheater branches, the so-called intakes, were considered. The steel is shielded against the hot process atmosphere by a two-layered build-up of refractory consisting of $115 \mathrm{~mm}$ thick bricks (fireclay, $30 \% \mathrm{Al}_{2} \mathrm{O}_{3}+65 \% \mathrm{SiO}_{2}$ ) on the gas side and, on the metal side, a ceramic thermoinsulation of calcium silicates having a high porosity and a thickness of $115 \mathrm{~mm}$.

Not only the metallic construction materials are subject to corrosion, but also the ceramic materials which provide both for heat insulation and for mechanical protection are increasingly attacked by the conditions exacerbated by the usage of secondary fuels. The development of materials with a high resistance to alkali-based corrosion was, therefore, in the focus of recent investigations [16].

To the best of our knowledge, the specific corrosion processes of mild steel in the preheater region of the cement production facility has not closely investigated hitherto. In this investigation, we aimed in contributing to a detailed characterisation of the occurring physicochemical conditions and the corrosion phenomena at the inner surface of the mild steel preheater cladding. Basically, the decision was supposed to be taken, whether high-temperature corrosion types would be active under operation conditions, similar to the situation in the rotary kiln [8]. Alternatively, the "normal" corrosion

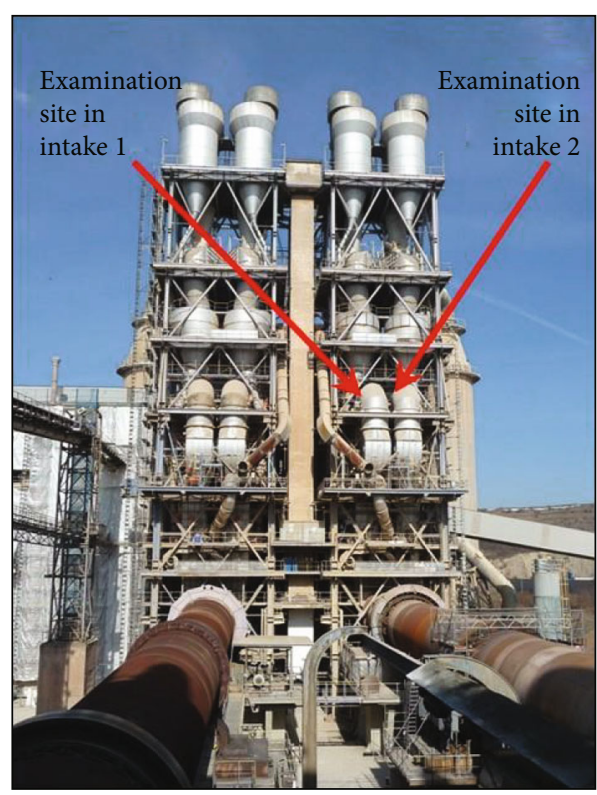

FIGURE 1: View of the two units of preheater (two intakes each) and the rotary kiln; location of the examination sites marked.

type comes into consideration, where (thin) liquid-water films are active associated with an electrochemical mechanism. Further, the role of aggressive chloride contamination was to be cleared up. To achieve this, five experimental approaches were designed:

(i) Exposure of prepared steel sheet samples at the examination sites of both intakes as a new manner of approach ("in-plant exposure"). These samples previously cut-out from the preheater cladding were given special pretreatments and inserted back into the corresponding cladding openings. The exposure periods amounted up to 24 months. Part of the steel surface kept uncoated, whilst the surface of the remaining area was coated for corrosion protection. These coatings were designed for hot corrosion and for aqueous electrochemical corrosion conditions, respectively. This issue will be treated separately

(ii) Collection of temperature and humidity data at the inner wall of the cladding at the examination sites of both intakes ("in situ logging"). The humidity, i.e., the presence of vaporous water, is the consequence of the combustion in the rotary kiln and, to less than $10 \%$, of the release by the raw products. These measurements aimed at gaining basic information about the conditions prevailing at the inner steel surface in the preheaters

(iii) Visual evaluation of the observed corrosion phenomena on the uncoated steel as well as analysis of the formed solid corrosion products focusing on morphology, composition, and phase identification ("multianalytical investigation"). This approach was followed in order to deduce the effective corrosion mechanism. Different methods were used, such 


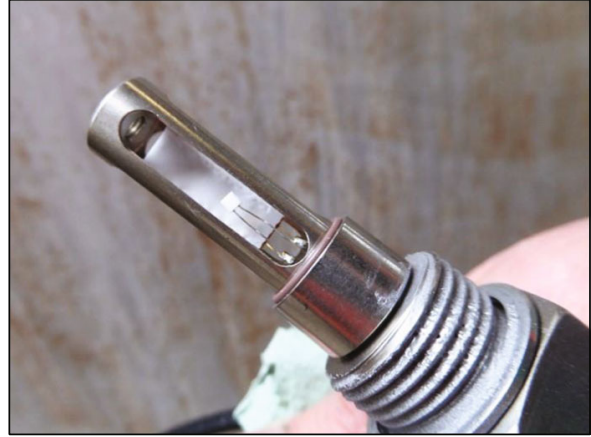

(a)

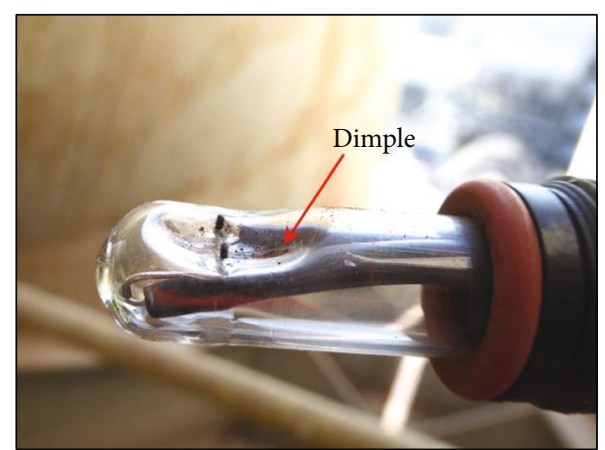

(b)

Figure 2: (a) Humidity sensor HC2-IE105 with its sensing elements after removal of the outer filter hull. (b) Custom-made conductivity sensor (second type).

as scanning electron microscopy combined with energy-dispersive X-ray analysis, infrared spectroscopy, Raman spectroscopy, X-ray diffraction, and Mö $\beta$ bauer spectroscopy

(iv) Determination of extractable species ("chemical contamination"). This was done using ion-coupled plasma optical emission spectrometry and ion chromatography

(v) Electrochemical laboratory measurements in selected chloride-containing model electrolyte solutions under varied aeration. This approach was employed by means of linear polarisation and electrochemical impedance spectroscopy in order to elucidate further characteristic features of the steel corrosion.

\section{Material and Methods}

2.1. In Situ Data Logging. For in situ data logging at the inner wall of the steel cladding, two sensor types were mounted in set-in nozzles. Hereby, the sensors were positioned in such a manner that the sought parameters could be recorded just at that place where the corrosion proceeds.

(i) Humidity sensor HC2-IE105 (Rotronic, Germany): based on a capacitive principle and additionally contains a temperature sensor (Figure 2(a))

(ii) Conductivity sensor: two custom-made types produced by Sensortechnik Meinsberg, Germany, detecting the presence of conductive liquids. The first had two platinum rings mounted on a glass cylinder, whereas the second contained two platinum wires fused in a shallow dimple, which forms a reservoir for condensed liquid (Figure 2(b)).

In addition to these measurements, cubical test samples of calcium silicate (Calsitherm Silikatbaustoffe $\mathrm{GmbH}$, Paderborn, Germany) were used for weighing experiments under defined temperature and humidity in a climate chamber (SH-242, Espec Europe GmbH, Germany).

2.2. Steel Samples, Pretreatment, and Exposure under InPlant Conditions. The in-plant exposure was done using four mild steel plates of $300 \mathrm{~mm} \times 150 \mathrm{~mm} \times 6 \mathrm{~mm}$ in size, which had been previously cut out from the designed places of the preheater cladding using an angle grinder. The inner surfaces of the plates were blasted using chilled iron grit (size 0.6$1.0 \mathrm{~mm}$ ), which gave a roughness of about $R_{\mathrm{z}}=80 \mu \mathrm{m}$. The areas to be exposed were divided into four stripe-like partial areas of $75 \mathrm{~mm}$ width each (Figure 3(a)). Herewith, not only the behaviour of bare mild steel was followed up, but also corrosion protection measures were supposed to be considered.

After being transported in a desiccator, the pretreated plates were mounted two by two into the corresponding cladding openings of both intakes (Figure 3(b)). The edges of the inserted samples were sealed against the penetration of rain and dust. The in-plant exposure periods were 6 and 12 months for the two plates exposed in intake 2 (designation M6/2 and M12/2, respectively), 18 and 24 months in intake 1 (M18/1, M24/1, respectively).

The secondary-fuel regime with burning tires, fluff, and liquid waste fuels was kept vastly constant within that twoyear period.

2.3. Multianalytical Post-Exposure Investigations. At first, the dismounted plates were visually inspected and photographically documented. To assess the corrosion rate, the material thinning was determined microscopically. Samples of the size $20 \mathrm{~mm} \times 20 \mathrm{~mm}$ were carefully cut out from the exposed large-area sheets using a band-saw in such a manner that both the corroded surface and the adjacent epoxy-coated, unattacked part (reference) were accounted for. The embedded cross-section was metallographically polished down to $3 \mu \mathrm{m}$ diamond and carefully etched ( $3 \%$ ethanolic $\mathrm{HNO}_{3}$ ). In order to reduce the influence of the indigenous surface roughness, a high number of equidistant measuring lines (every $250 \mu \mathrm{m}$ ) was overlaid to the primary images, which were taken by a VHX-1000 digital Keyence microscope. The physicochemical analysis of solid corrosion products (CP) originated in the kiln was performed on compact steel-based samples and on loose CP powder materials after manually milling using an agate mortar. Loose corrosion product layers could be easily collected, and adhering parts were carefully scratched off from the base metal. Typical 


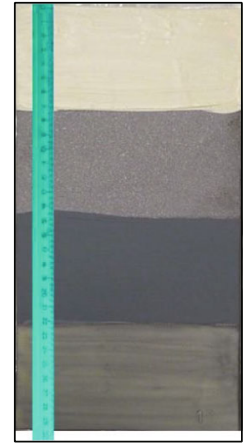

(a)

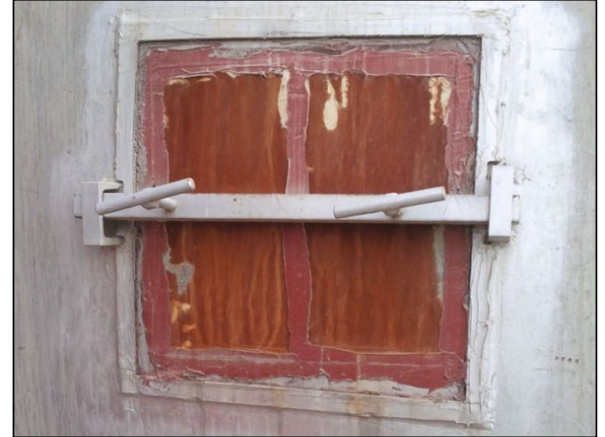

(b)

Figure 3: (a) Top view of one of the four steel plates as prepared for in-plant exposure; description of the stripes (top-down): Hempadur epoxy coating; no coating, surface blasted only; Galvosil coating; and Galvosil binder coating without zinc powder, manual painting. (b) Two plates after fixture in the cladding of intake 1 (six months after exposure start).

areas were selected, where the size was in the magnitude of $1-2 \mathrm{~cm}^{2}$.

(i) Scanning electron microscopy (SEM): following a thin carbon coating, the images of compact $\mathrm{CP}$ were taken on a DSM 982 Gemini (Zeiss, Germany) provided with a field emission cathode, with an acceleration voltage of $2-15 \mathrm{keV}$. Energy-dispersive $\mathrm{X}$-ray spectroscopy (EDX) for elemental analyses were done using a Voyager 3000 spectrometer (Noran, USA) provided with a $\mathrm{Si}(\mathrm{Li})$ detector

(ii) Infrared spectroscopy (IR): the usual transmission technique with $\mathrm{KBr}$ pellets was applied, where the fraction of the powdered substance to be analysed was $2-3 \%$. The spectra were recorded down to $370 \mathrm{~cm}^{-1}$ averaging 5 single spectra using a Spectrum 2000 (PerkinElmer, Germany)

(iii) Raman spectroscopy (RS): the analyses were run on a RFS 100/S instrument (Bruker, Germany) combined with a Nd-YAG $1024 \mathrm{~nm}$ laser generator (Coherent, USA). The wavelength range was generally 500$3000 \mathrm{~cm}^{-1}$ with the beam energy as low as possible to avoid radiation damage

(iv) Differential scanning calorimetry (DSC): a DSC 404 instrument (Netzsch, Germany) was used for a few powdered $\mathrm{FeOOH}$ and $\mathrm{CP}$ samples $(10 \mathrm{~K} / \mathrm{min})$.

(v) X-ray diffraction (XRD): diffractograms of powdered CPs were recorded using an RD7 instrument (Seifert-FPM, Germany) provided with an iron tube $(\mathrm{FeK} \alpha 10.1936087 \mathrm{~nm}, \mathrm{FeK} \alpha 20.1940025 \mathrm{~nm} ; 30 \mathrm{kV}$, $28 \mathrm{~mA}$ ). The stepscan covered $0-100^{\circ}(2 \theta)$ with a rate of $0.02^{\circ} / 4 \mathrm{~s}$. These measurements were performed at the University of Applied Sciences Dresden

(vi) Mößbauer spectroscopy (MS): measurements were performed in transmission geometry using powdered samples. In a first approach, a Wissel system at HZDR was used. Further measurements were performed at IFJ PAN using a home-built setup provided with a ${ }^{57} \mathrm{Co}$ source in rhodium matrix.
The samples were sandwiched between thin mica slices. All experiments were performed at ambient temperature. The obtained Mößbauer spectra were fitted with a Voigt-based fitting routine [17] that allows to determine the distribution of hyperfine fields under the assumption of linear relationships between the width of magnetic hyperfine field and the width of other hyperfine interaction parameters, such as quadrupole and isomer shifts. Since it does not influence the main information, which is the identification of phases and its concentration, it was decided not to include these data into the paper. All spectra were fitted consecutively, starting with the most relevant components with well-defined parameters. Then, the parameters of other phases were gradually introduced.

For the identification of the in-plant formed CP phases, as described above, several commercial substances were utilised:

(i) Goethite, $\alpha$-FeOOH (Bayferrox 910; Lanxess, Germany)

(ii) Lepidocrocite, $\boldsymbol{\gamma}$-FeOOH (Bayferrox 943)

(iii) Magnetite, $\mathrm{Fe}_{3} \mathrm{O}_{4}(98 \%+,<50 \mathrm{~nm}, \# 637106-25 \mathrm{G}$, Sigma-Aldrich, Germany)

(iv) Hematite, $\alpha$ - $\mathrm{Fe}_{2} \mathrm{O}_{3}$ (z.A., Ferak, Germany).

In addition to these powder materials, Akaganeit, $\beta$ $\mathrm{FeOOH}$, was produced in laboratory following slightly different recipes [18]. The mostly utilised product was generated by dissolution of $27 \mathrm{~g} \mathrm{FeCl}_{3} \cdot 6 \mathrm{H}_{2} \mathrm{O}$ in $1 \mathrm{~L}$ deionised water, then warmed up to $40^{\circ} \mathrm{C}$ and stirred for 48 hours. The precipitated product was filtered off, gently rinsed, and dried at ambient temperature.

Besides the CPs, the thin coverings that had been formed on the conductivity sensors were analysed in terms of chemical contaminants using ion-coupled plasma optical emission spectrometry (ICP-OES) (Optima 4300 DV; PerkinElmer, Germany), three single determinations 
each, and ion chromatography (IC) (ICS 900; DIONEX, Germany). The preceding extraction was accomplished by storing for four weeks in deionised water followed by filling up to $10 \mathrm{~mL}$.

2.4. Electrochemical Investigations. Electrochemical laboratory investigations were carried out using a special threeelectrode cell in combination with a CompactStat.e 10800 instrument (Ivium, Netherlands). Rolled mild steel sheet (1.0037, thickness $2 \mathrm{~mm}$ ) was utilised as working electrode with sample sizes of $26 \mathrm{~mm} \times 38 \mathrm{~mm}$. The surface was degreased with acetone or, in a few cases, wet-ground (P800). The cell consisted of two polymethylmethacrylate blocks (base area $70 \mathrm{~mm} \times 70 \mathrm{~mm}$ ), which were screwed together clamping the samples in between. The upper cell part contained a tightening O-ring (inner diam. $5 \mathrm{~mm}$, exposed area $0.2 \mathrm{~cm}^{2}$ ) and a glued-in plastic tube for the solution $(30 \mathrm{~mL})$, whilst the lower part provided for the electric connection. The cell was completed by a platinum sheet counter electrode and a type $\mathrm{Ag} / \mathrm{AgCl}, \mathrm{KCl}$ sat. reference electrode (Sensortechnik Meinsberg, Germany), the potential of which against the standard hydrogen electrode is $E_{\mathrm{H}}=0.20 \mathrm{~V}$, slightly depending on temperature [19]. A Faraday cage served for shielding against disturbing electromagnetic fields.

The model electrolytes $1 \mathrm{M} \mathrm{KCl}, 0.1 \mathrm{M} \mathrm{KCl}$, and $0.1 \mathrm{M}$ $\mathrm{K}_{2} \mathrm{SO}_{4}$ were applied. The measurements were performed in (i) unstirred solutions under air access, (ii) under forced aeration, and (iii) under deaeration, which was put into practice by gentle pressurised-air purge and pure-nitrogen gas bubbling, respectively, at ambient temperature. Part of the measurements was done at $40^{\circ} \mathrm{C}$.

Linear polarisation experiments were performed after giving the system an ample time of $10 \mathrm{~min}$ for developing a stable stationary state (open circuit potential ocp). Mainly, the polarisation was run from the cathodic region into the anodic direction using a rate of $1 \mathrm{mV} / \mathrm{s}$, at least in duplicate using fresh specimens. The polarisation resistance $R_{\mathrm{p}}$ was determined according to the Stern-Geary method using the routine implemented in IviumSoft. The respective Tafel slopes $b_{c, a}$ were utilised for calculating the corrosion density $j_{\text {corr }}$ according to the well-known Stern-Geary equation [20].

$$
j_{\text {corr }}=\frac{b_{c} \cdot b_{a}}{2.3 \cdot\left(b_{c}+b_{a}\right) \cdot R_{p}} .
$$

Impedance spectroscopy (EIS) was performed at ocp in the frequency range of $50 \mathrm{kHz}$ down to $0.5 \mathrm{mHz}$ with 10 frequency points per decade and an amplitude (peak-to-zero) of $20 \mathrm{mV}$. The reference electrode was provided with a capacitive bridge $(1 \mu \mathrm{F})$ to avoid disturbances in the highfrequency region [21]. Usually, serial scans were recorded at defined time up to five weeks of immersion in order to follow the effect of increasing corrosion. Again, at least two parallel series were measured. The evaluation in this presentation refers to spectra recorded for immersion periods of $3 \mathrm{~h}$. For modelling, the data were exported into the ZView software (Scribner) and analysed based on different equivalent circuits.

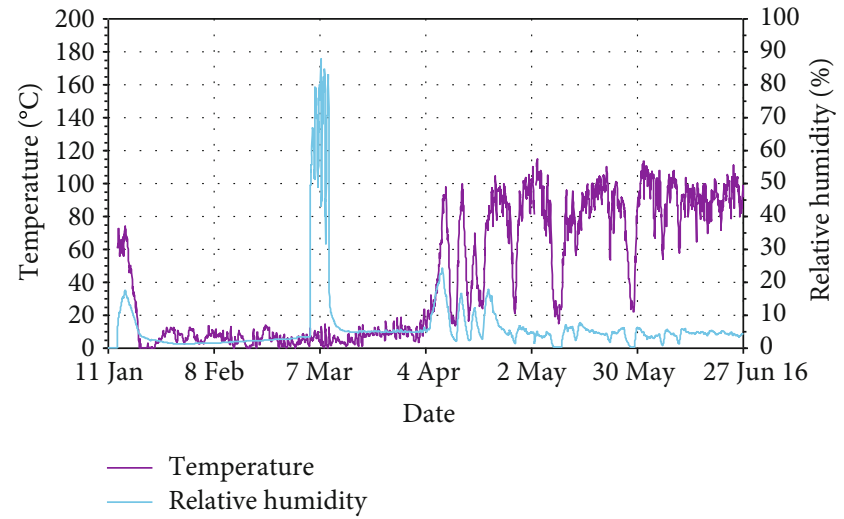

FIgUre 4: Courses of temperature (intake 1) and relative humidity (intake 2) in the period Jan-Jun 2016. Both quantities refer to different intakes due to limited on-site wiring. The humidity excursion in the beginning of March 2016 is due to testing the sensor at free atmosphere.

\section{Results and Discussion}

3.1. In Situ Logging of Temperature and Humidity. The temporal course of the temperature and the relative humidity is displayed in Figure 4. The diagram makes clear that the regular operation of the facility is accompanied with a temperature level of $100-110^{\circ} \mathrm{C}$ at the inner surface of the steel mantle, just there, where the corrosion investigations were carried out. This relatively low temperature level presupposes, of course, the presence of the adjacent ceramics, which act as effective thermal insulation against the interior of the preheater with process temperatures of about $800^{\circ} \mathrm{C}$. Thus, it can be derived from the temperature findings that typical hot-gas corrosion phenomena are definitely excluded for the examination sites. Rather, the type of corrosion is designated as "aqueous corrosion" with an electrochemical mechanism under elevated temperatures.

Figure 4 addresses a second point of interest, namely the relation between temperature and humidity, as determined by the special sensor(s) set in the preheater mantle. On the very left-hand side of the diagram, the high temperature signalises the last phase of the operating state in January 2016 before the onset of shut-down, which is usually planned for wintertime. It may be seen that along with the decrease of temperature also the humidity decreases. Correspondingly, the temperature movements after onset of operation in the beginning of April 2016-three raises and three short-time interruptions-are associated with in-phase movements of the relative humidity, i.e., a maximum of the relative humidity occurred when a temperature maximum was observed and vice versa. After some time, the humidity changes diminish in their amplitudes, although temperature minima keep linked with those of the relative humidity until the end of the records.

However, it was expected that shut-down and coolingdown would lead to an increase of the relative humidity with the consequence that the vaporous water condenses on the relatively cooler kiln cladding. To explain the contrary findings, a set of laboratory measurements was designed to follow 
up the weight changes of a sample of the practically established calcium silicate. Starting from $20^{\circ} \mathrm{C}$ and $50 \%$ relative humidity, the cube specimens were kept for $18 \mathrm{~h}$ under the designed conditions and weighted directly afterwards. As seen in Figure 5, the ceramic releases humidity for temperatures higher than $40^{\circ} \mathrm{C}$. Accordingly, a higher humidity will be present in the gap between ceramics and steel cladding under conditions of temperature increase and vice versa. Obviously, these in-phase changes of relative humidity and temperature occur, although the solubility of the gas for vaporous water enhances with increasing temperature.

The conductivity sensors were to collect aqueous solution as a consequence of potential condensation, which was thought to happen at the kiln mantle as the relative coldest part of the system. However, the recorded conductivity data, covering a period of 20 months, were typically at the lower limit and not quantitatively assessable in the intended manner. Correspondingly, no liquid could be detected, when the sensors were inspected after shut-down. All in all, these findings agree with those of the humidity measurements and the explanation derived.

\subsection{Appearance of the Steel Plates following the In-Plant} Exposure in the Preheater Zone. After in-plant exposure of 6 to 24 months, the uncoated steel areas were covered with thick rust layers. The images of Figure 6 give an idea of their appearance. Comparing their structure and compactness, differences can be seen at a glance. The plates M6/2 and M12/2 show CP layers that consist two portions, an upper fraction with more or less spalling character and a lower fraction that is well adherent to the metallic substrate. This feature is clearly seen in Figure 6(b) for the state $M 12 / 2$. Contrarily, the plates M18/1 and M24/1 embody a less degradation, where spalling phenomena of the CP are much less present. That means that the general degradation has proceeded in a different manner, which does not mainly correspond to the varied length of exposure, as was initially assumed. Instead, there is, obviously, a greater influence of the special location of the exposure of the plates. This statement will be discussed later on.

3.3. Corrosion Rate. The amount of the wall thickness reduction per specimen during exposure was estimated metallographically (Figure 7) as described in the Materials and Methods. The respective mean values of at least 50 material thickness data $x_{i}$ were subtracted from each other and compiled in Table 1 together with their standard errors $S E$ according to equation (2) [22]: $s$ : standard deviation, $n$ : sample size.

$$
S E=\frac{s}{\sqrt{n}}=\sqrt{\frac{\sum_{i=1}^{n}\left(x_{i}-\bar{x}\right)^{2}}{n(n-1)}} .
$$

The data of Table 1 make clear that, in accordance with the heterogeneous images of the corroded surfaces (Figure 6), a relative high degree of scattering has to be supposed for the local corrosion rates. Obviously, the four prepared samples reveal an incorrect relation for increas-

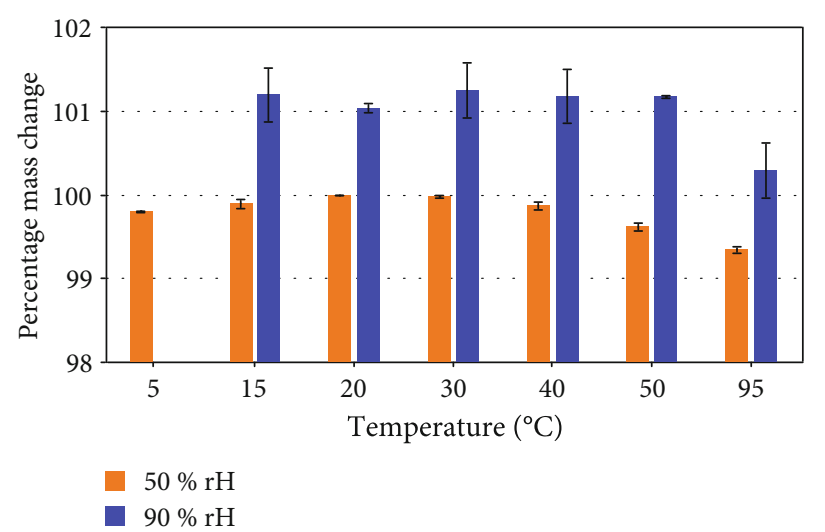

FIgURE 5: Water sorption/desorption properties of cubical calcium silicate samples $\left(50 \times 50 \times 50 \mathrm{~mm}^{3}\right)$ determined by storage under defined temperature and humidity conditions followed by instantaneous weighing. The mass at $20^{\circ} \mathrm{C}$ and $50 \%$ relative humidity was arbitrarily set as starting point and reference state.

ing exposure time by chance, because the overall thickness loss will undoubtedly grow with increasing time under the respective surrounding conditions. Nevertheless, it must be stated that the intake proves again to be an initially not expected dominant influence factor on the corrosion rate: The absolute corrosion attack in case of the plates exposed in intake 2 is clearly higher, although the exposure time was lower compared to intake 1 . Therefore, the corrosion rates in both intakes differ very much.

3.4. Multianalytical Investigations of the Corrosion Products. These investigations aim at gaining information about the micromorphological features of the different CPs as well as about their element status and phase composition.

\subsubsection{Scanning Electron Microscopy and Local Element} Analysis. Generally, the outer surfaces of the four samples are characterised by a markedly heterogeneous appearance in SEM, similarly as stated in [23]. Highly crystalline areas alternate with compact gel-like areas. The crystals encountered show quite different forms, such as platelets, leaf-like crystals, columnar and needle-like structures, and cubes. It could be often observed that zooming-in gives evidence of finer substructures.

The first group of results as displayed in Figure 8 relates to the sample M6/2, which had undergone a six-month operation regime without wintertime interruption. Figure 8(a) depicts an area on the outer surface of the loose CP layer with differently compact/crystalline regions. The corresponding elemental analyses revealed pronounced peaks of iron, oxygen, and chlorine, with the $\mathrm{Cl}$ concentrations ranking EDX2 > EDX1 > EDX3 (Figures 8(a)-8(c)). As for the lower, adherent layer (Figure $8(\mathrm{~d})$ ), both investigated sites were found to have relatively high $\mathrm{Cl}$ contents in spite of their different morphological shapes (Figures 8(e) and 8(f)). All in all, both parts of the CP layers stemming from intake 2 showed a variety of crystalline shapes, ranging from flimsy platelets over rods to feather-like forms, mostly grown together. 


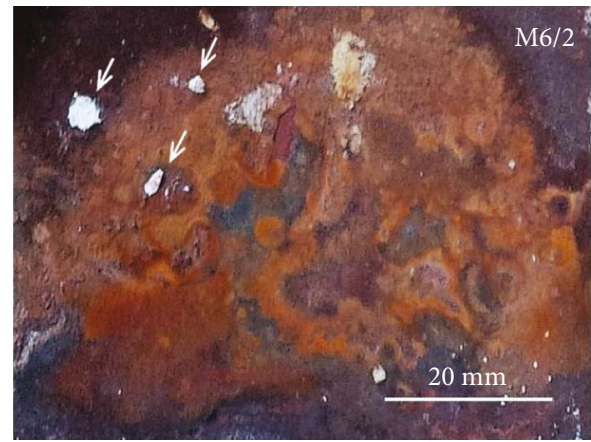

(a)

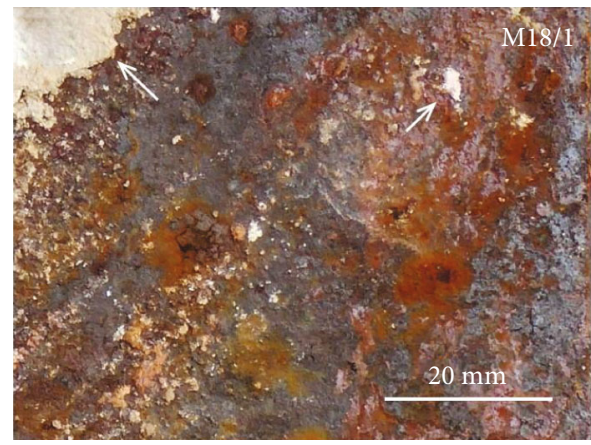

(c)

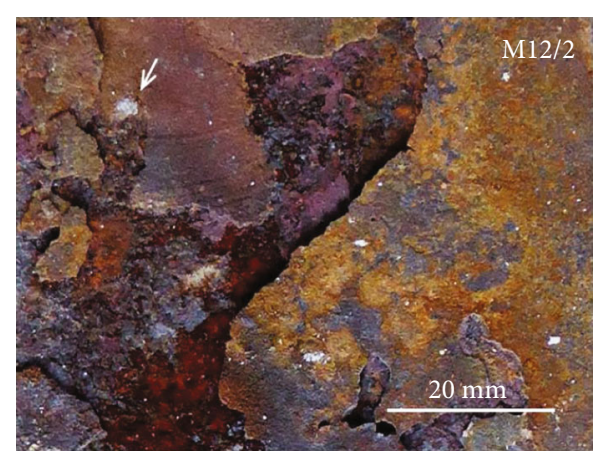

(b)

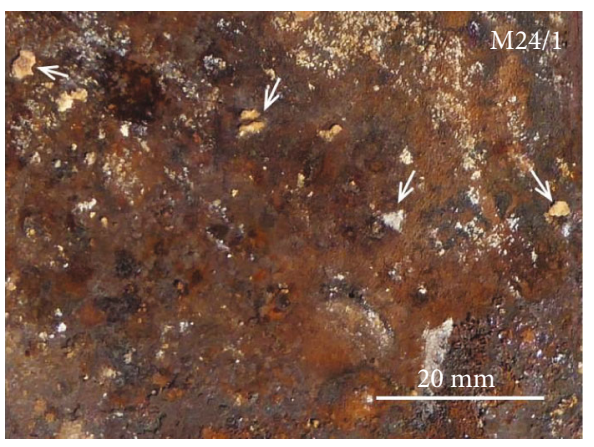

(d)

Figure 6: Macroimages of the uncoated areas after exposure. Small light regions on most of the plates (white arrows) are spalled particles from other regions of the plates or ceramic material of the thermal insulation due to direct contact.

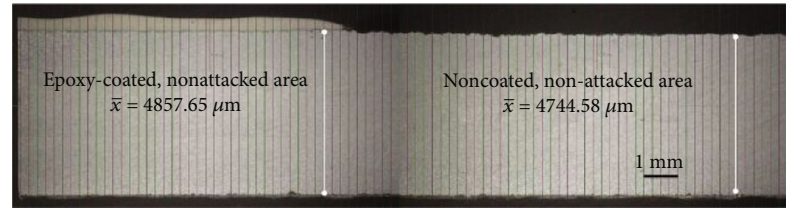

Figure 7: Cross-section of a sample from exposed plate M12/2 provided with an overlaid metallographic measurement grid. Two selected lines demonstrate the principle of determining the corrosion attack.

TABLE 1: Amount of corrosion attack according to metallographic measurements on one cross-section of each plate. Differences of the respective thickness mean values provided with their standard errors (cf. Figure 7, equation (2)).

\begin{tabular}{lc}
\hline Sample & Thickness loss $(\mu \mathrm{m})$ \\
\hline M6/2 & $(158 \pm 9)$ \\
M12/2 & $(113 \pm 8)$ \\
M18/1 & $(46 \pm 7)$ \\
M24/1 & $(36 \pm 7)$ \\
\hline
\end{tabular}

Samples M18/1 and M24/1 from intake 1 were characterised by a higher noncrystalline fraction on the outer surface associated with minute $\mathrm{Cl}$ contents smaller than that for samples from intake 2 (Figures $8(\mathrm{~g})$ and $8(\mathrm{~h})$ ). This agrees with the contamination results shown in Figure 9.

3.4.2. Infrared and Raman Spectroscopy. The IR spectroscopic results obtained for the five utilised reference materials in transmission geometry show a generally very good agreement of the band positions with literature data, based both on synthesised compounds [18, 24-26] and on CPs and others $[27,28]$. As Table 2 indicates, the bands of the FeOOH modifications differ from each other in a sufficient manner, whereas the spectra of $\mathrm{Fe}_{3} \mathrm{O}_{4}$ and $\alpha-\mathrm{Fe}_{2} \mathrm{O}_{3}$ are somewhat similar in the region of $500-600 \mathrm{~cm}^{-1}$. Interestingly, the magnetite spectrum is partly missing in compilations [18]. It appears to be somewhat critical in its IR signature. As for $\beta-\mathrm{FeOOH}$, the comparison with the full spectrum displayed in ref. [18] evidences the presence of the rodlike crystallised form.

The results for the CPs are shown in Figure 10. For the CPs of samples M6/2 and M12/2, considerable amounts of hematite $\left(\alpha-\mathrm{Fe}_{2} \mathrm{O}_{3}\right)$ are found. Hematite is present in both fractions of the CPs (upper/loose and lower/adherent fractions). On sample M6/2, both fractions contain additionally akaganeite $(\beta-\mathrm{FeOOH})$. Contrarily, the upper, loose $\mathrm{CP}$ fraction of M12/2 reveals no sure indication of any $\mathrm{FeOOH}$, whereas the adherent fraction appears to contain $\alpha$ - and $\gamma$-FeOOH. Certain differences in the phase state may be present between $\mathrm{M} 6 / 2$ and $\mathrm{M} 12 / 2$, because the former had undergone an exposure under sole operation conditions in contrast to the latter that was subjected also to a two-month shut-down period.

On the contrary, the CPs of the samples M18/1 and M24/1 have a quite deviating composition in that hematite appears to be vastly or completely substituted by magnetite, as it is attested by the missing band at $460 \mathrm{~cm}^{-1}$ and, macroscopically, by magnetic properties of the powdered CP. This 


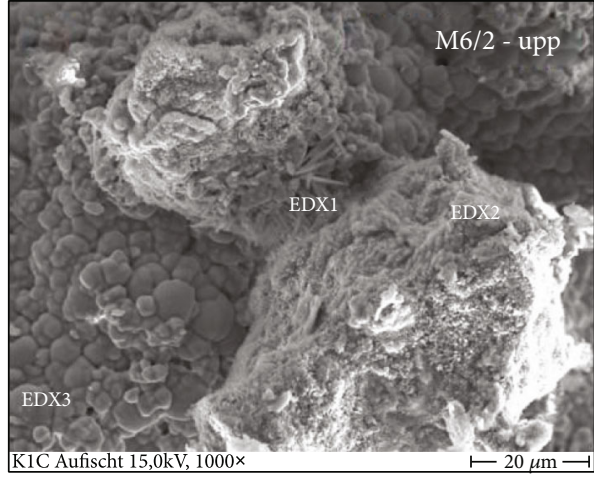

(a)

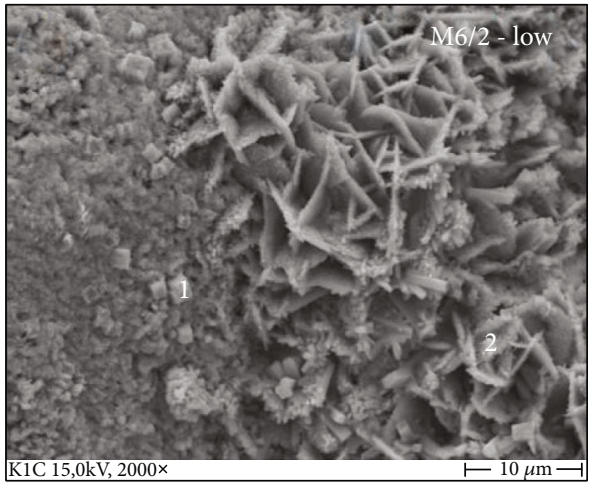

(d)

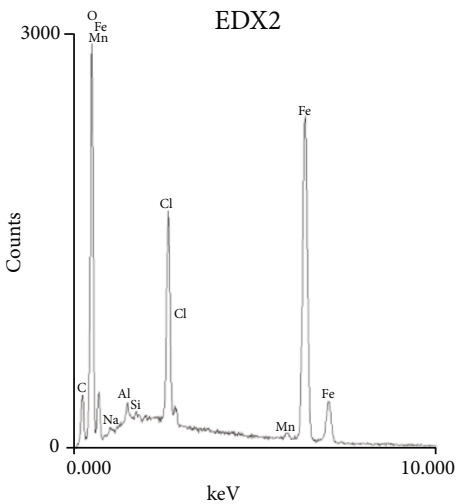

(b)

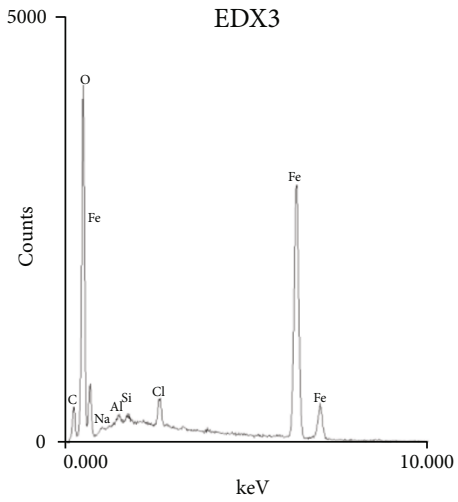

(c)

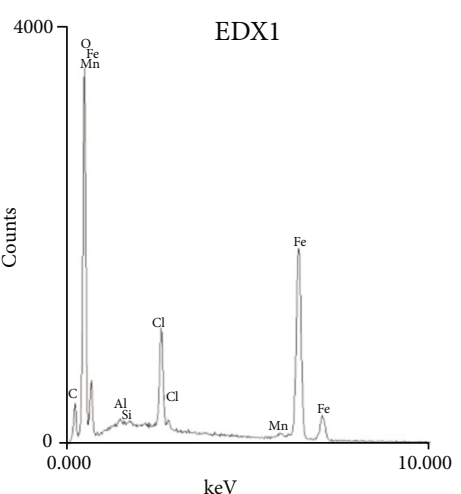

(e)

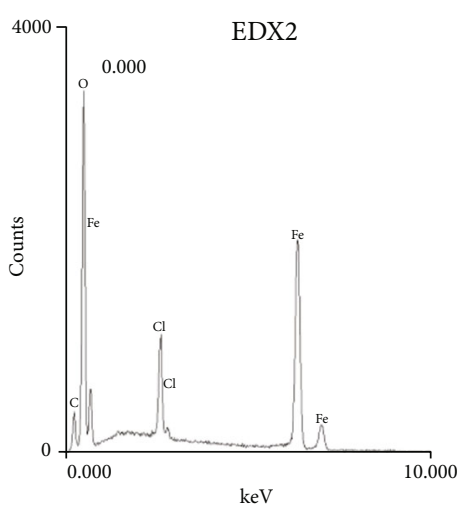

(f)

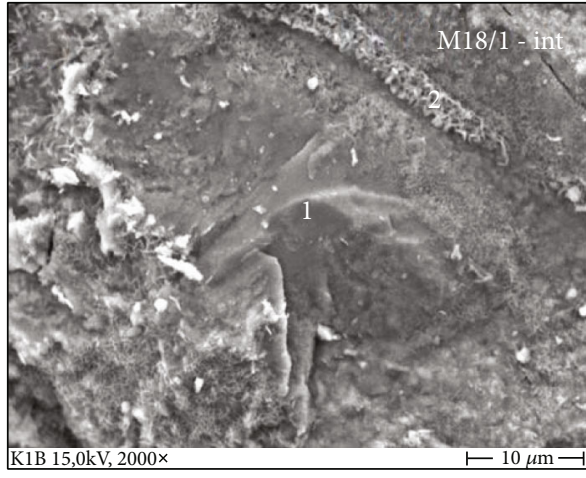

(g)

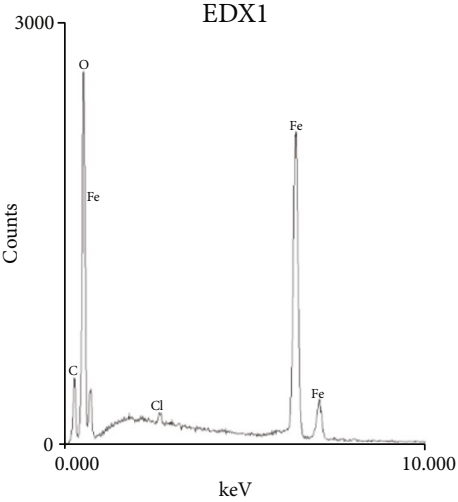

(h)

FIGURE 8: SEM images and corresponding EDX spectra; $(\mathrm{a}-\mathrm{c})$ referring to the outer surface of the upper, loose CP layer of sample M6/2 (spectrum of EDX1 not shown), (d-f) referring to the lower, adherent CP layer of sample M6/2, and (g-h) referring to the integral layer of M18/1. Spectra regions beyond $10 \mathrm{keV}$ (right edge of the diagram) were free of any signals and, hence, cut off.

fact is not explainable by the higher exposure times. Instead, it points to differing operating conditions in the plant. This detail will be discussed later. Moreover, goethite $(\alpha-\mathrm{FeOOH})$ and lepidocrocite $(\gamma$ - $\mathrm{FeOOH})$ are present.

Raman spectroscopic data are shown in Figure 11, again focused on the most relevant wavenumber region. As for the positions of the reference compounds, the major peaks agree with literature data $[18,26,29-31]$. Interestingly, magnetite $\left(\mathrm{Fe}_{3} \mathrm{O}_{4}\right)$ was characterised as a weak Raman scatterer
[26]. Moreover, it is easily subject to laser-based in situ oxidation. The spectra recorded confirm the presence of $\alpha-\mathrm{Fe}_{2} \mathrm{O}_{3}$ in the cases of M6/2 and M12/2 very clearly. Astonishingly, the indication of $\mathrm{FeOOH}$ phases as minor components in the CPs by this technique proves to be difficult. The measurements of the pure reference materials suggest that the sensitivity for hematite is perceptibly higher than in the case of the $\mathrm{FeOOH}$ compounds. It appears that the acquisition time would have to be considerably higher. 


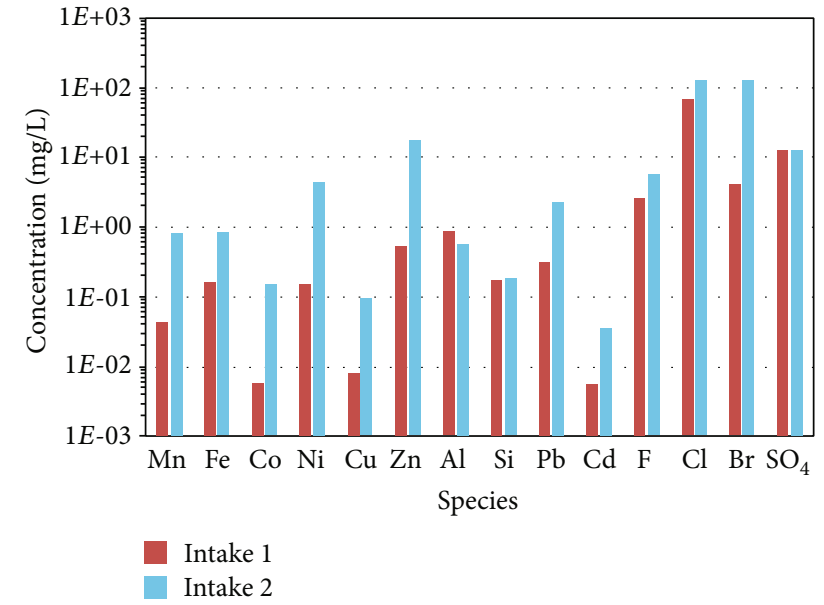

FIgURE 9: Concentrations (logarithmic plot) for selected chemical species determined in aqueous extraction solutions from the conductivity sensors; metal ion species according to ICP-OES, and anion concentrations according to IC.

TABle 2: Transmission minima of the IR bands determined for reference compounds.

\begin{tabular}{lc}
\hline Phase & Band position $\left(\mathrm{cm}^{-1}\right)$ \\
\hline$\alpha$-FeOOH & 798,899 \\
$\beta$-FeOOH & $660-670,846$ \\
$\gamma$-FeOOH & 748,1024 \\
$\mathrm{Fe}_{3} \mathrm{O}_{4}$ & 558,620 (shoulder) \\
$\alpha-\mathrm{Fe}_{2} \mathrm{O}_{3}$ & $459,535,600$ (shoulder) \\
\hline
\end{tabular}

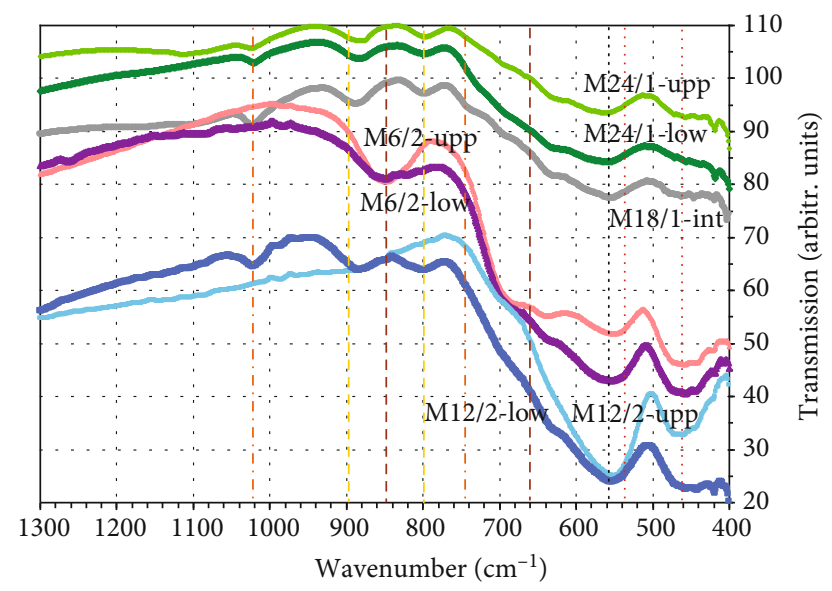

FIGURE 10: IR spectra (cut-out) for powdered CPs. -upp: upper CP fraction; -low: lower CP fraction; -int: integral fraction. Experimental band positions for the reference materials are marked by dashed lines (cf. Table 2).

The $\mathrm{CP}$ composition of M18/1 was quite different from those with M6/2 and M12/2. Hematite is missing, whereas magnetite is indicated. This confirms the finding obtained with the infrared measurements.

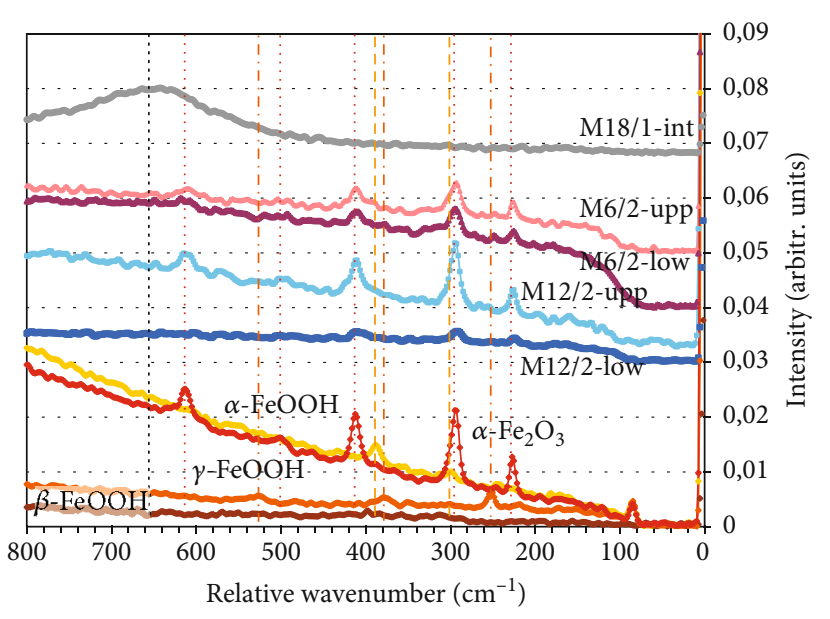

FIgURE 11: Raman spectrometric results for powdered CPs and reference substances; designations like for Figure 10. Experimental peak positions for reference materials are marked by dashed lines; for $\mathrm{Fe}_{3} \mathrm{O}_{4}$ at ca. $660 \mathrm{~cm}^{-1}$ taken from reference $[26,27$.

3.4.3. X-Ray Diffraction. Diffraction recordings were taken from CPs of M6/2-upp, M12/2-upp, M18/1-int, M24/1upp, and M24/1-low.

Whilst a mixture of a ferric oxide hydroxide (to be specified as $\beta$ - $\mathrm{FeOOH}$ referring to the original literature $[32,33])$ and hematite $\left(\alpha-\mathrm{Fe}_{2} \mathrm{O}_{3}\right)$ was found for the CP samples from intake 2 (Figure 12(a)), the diffraction pattern of the samples from intake 1 proved to be substantially different. Here, a mix of $\mathrm{FeOOH}$ phases and magnetite $\left(\mathrm{Fe}_{3} \mathrm{O}_{4}\right)$ was present (Figure 12(b)).

3.4.4. Mößbauer Spectroscopy. The results shown here were obtained at IFJ PAN as described in the Multianalytical Investigations. Fit-relevant data were additionally taken from references [34-37]. The discussion focuses on one sample of each intake. Figures 13(a) and 13(b) display results for the different CP fractions of M12/2.

The spectrum for the upper, loose $\mathrm{CP}$ fraction is dominated by the sextet of hematite $\left(\alpha-\mathrm{Fe}_{2} \mathrm{O}_{3}\right)$, which exhibits hyperfine parameter values close to those observed in reference [37]. The quantification gives $95 \%$ of the iron compounds (Table 3), i.e., the overwhelming portion. A residue of about $5 \%$ is ascribed to akaganeite $(\beta-\mathrm{FeOOH})$ or lepidocrocite $(\gamma-\mathrm{FeOOH})$. Due to the peak broadening, the two phases cannot be distinguished, since they have very close hyperfine parameters at room temperature. This uncertainty holds also for more or less large portions of the other selected CP samples.

The lower, adherent part of M12/2 shows a markedly deviating spectrum (Figure 13(b), Table 3). In particular, magnetite $\left(\mathrm{Fe}_{3} \mathrm{O}_{4}\right)$ was identified in addition to hematite. The spectrum of magnetite is characterised by two sextets based on the simultaneous presence of ferrous and ferric ions in the inverse spinel lattice. From the thermodynamical point of view, the presence of magnetite in the neighbourhood of the metal substrate is a necessary issue; this will be discussed in the next section. In addition to the mentioned phases, the lower CP fraction of M12/2 contains a rest that was fitted 


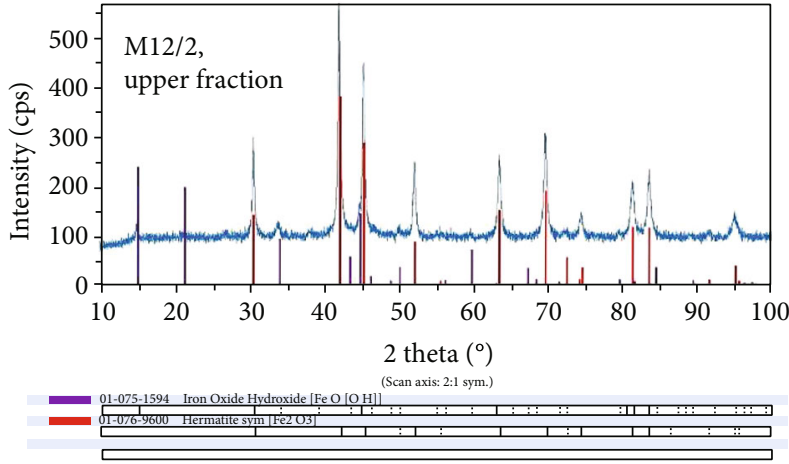

(a)

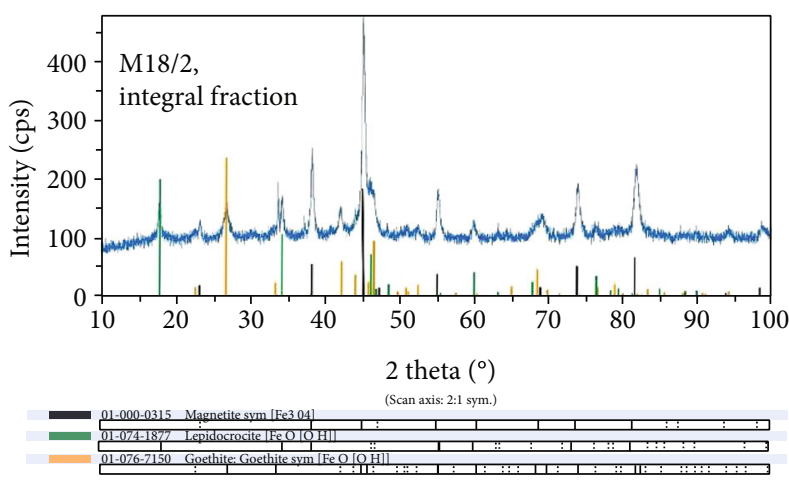

(b)

Figure 12: X-ray diffractograms of powdered CPs of M12/2, upper fraction (a), and M18/1, integral fraction (b); reference lines augmented for the sake of perceptibility.

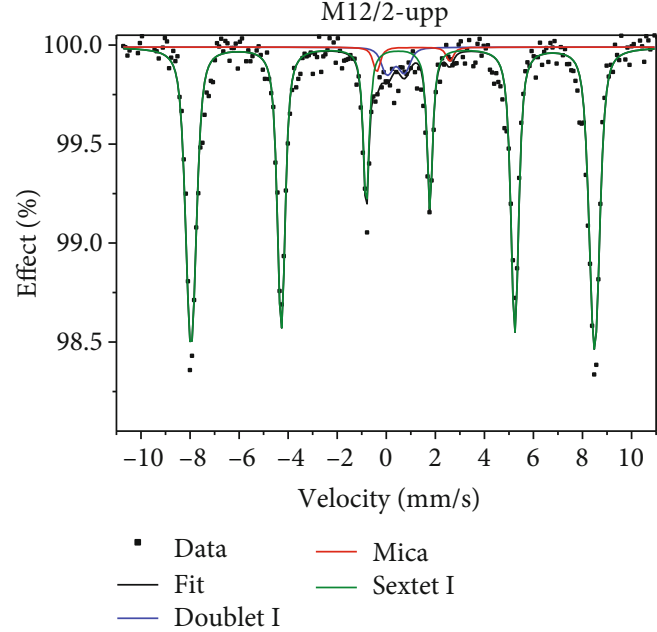

(a)

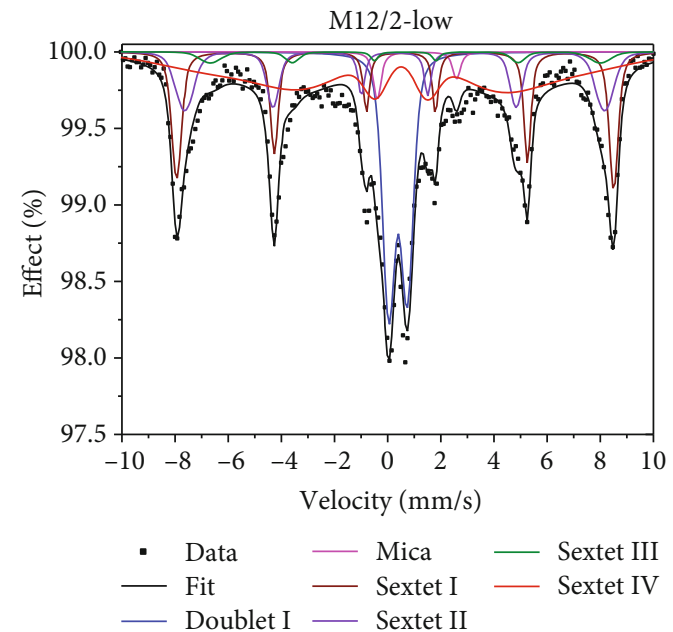

(b)

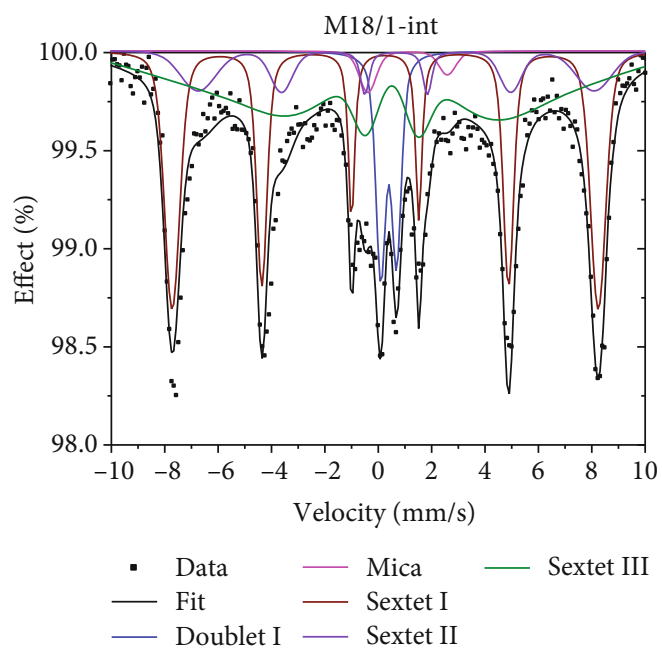

(c)

Figure 13: Mößbauer spectra for powdered CPs of M12/2, upper (a) and lower (b) fractions, and M18/1, integral fraction (c), along with the fitting results.

assuming the presence of goethite $(\alpha-\mathrm{FeOOH})$ (Table 3$)$. However, the fitting process suggested a modification of the original sextet. Literature indicates that dispersion of particle sizes, imperfect crystallinity, and/or deviations from stoichiometry may lead to distorted sextets and hyperfine field distribution, especially at room temperature [28, 38, 39]. 
TABLE 3: Compiled results for Mö $\beta$ bauer-derived phase compositions of the samples M12/2, upper and lower fractions, and M18/1, integral fraction, along with the fit-based quantification. $\delta$ : isomer shift; $\Delta E_{\mathrm{Q}}$ : electric quadrupole split; $B_{\mathrm{hf}}$ : magnetic hyperfine field.

\begin{tabular}{|c|c|c|c|c|c|c|}
\hline Sample & Component & $\delta(\mathrm{mm} / \mathrm{s})$ & $\Delta E_{\mathrm{Q}}(\mathrm{mm} / \mathrm{s})$ & $B_{\mathrm{hf}}(\mathrm{T})$ & Phase & Fraction (\%) \\
\hline \multirow{3}{*}{ M12/2 upper CP fraction } & Doublet I & 0.39 & 0.69 & & $\beta$ - or $\gamma$-FeOOH & 5 \\
\hline & Doublet II & 1.10 & 2.98 & & Mica & 2 \\
\hline & Sextet I & 0.37 & -0.11 & 51 & $\alpha-\mathrm{Fe}_{2} \mathrm{O}_{3}$ & 93 \\
\hline \multirow{6}{*}{ M12/2 lower CP fraction } & Doublet I & 0.39 & 0.69 & & $\beta$ - or $\gamma$-FeOOH & 23 \\
\hline & Doublet II & 1.10 & 2.98 & & Mica & 2.5 \\
\hline & Sextet I & 0.39 & -0.11 & 51 & $\mathrm{Fe}_{2} \mathrm{O}_{3}$ & 20 \\
\hline & Sextet II & 0.26 & & 49 & \multirow{2}{*}{$\mathrm{Fe}_{3} \mathrm{O}_{4}$} & \multirow{2}{*}{18.5} \\
\hline & Sextet III & 0.66 & & 45.5 & & \\
\hline & Sextet IV & 0.38 & -0.13 & 38 & $\alpha$-FeOOH & 36 \\
\hline \multirow{5}{*}{ M18/1 integrated fraction } & Doublet I & 0.39 & 0.59 & & $\beta$ - or $\gamma$-FeOOH & 10 \\
\hline & Doublet II & 1.10 & 2.98 & & Mica & 3 \\
\hline & Sextet I & 0.26 & & 49.5 & \multirow{2}{*}{$\mathrm{Fe}_{3} \mathrm{O}_{4}$} & \multirow{2}{*}{47} \\
\hline & Sextet II & 0.67 & & 46.0 & & \\
\hline & Sextet III & 0.38 & -0.13 & 38 & $\alpha$-FeOOH & 40.5 \\
\hline
\end{tabular}

TABle 4: Compiled analytical results for the CPs (goe.: goethite $\alpha$-FeOOH; aka.: akaganeite $\beta$-FeOOH; lep; lepidocrocite $\gamma$-FeOOH; mag.: magnetite $\mathrm{Fe}_{3} \mathrm{O}_{4}$; hem.: hematite $\alpha-\mathrm{Fe}_{2} \mathrm{O}_{3}$ ).

\begin{tabular}{|c|c|c|c|c|}
\hline Sample & IR spectroscopy & Raman spectroscopy & XRD & Möß $\beta$ bauer spectroscopy \\
\hline $\begin{array}{l}\text { M6/2-upp } \\
\text { M6/2-low }\end{array}$ & $\begin{array}{l}\text { hem. + aka. } \\
\text { hem. + aka. }\end{array}$ & $\begin{array}{l}\text { hem. + lep. } \\
\text { hem. + lep. }\end{array}$ & $\begin{array}{c}\text { hem. + aka. } \\
-\end{array}$ & $\begin{array}{c}\text { hem. + aka./lep. } \\
\text { hem. + mag. + aka./lep. }\end{array}$ \\
\hline $\begin{array}{l}\text { M12/2-upp } \\
\text { M12/2-low }\end{array}$ & $\begin{array}{c}\text { hem. } \\
\text { hem. + goe. + lep. }\end{array}$ & $\begin{array}{l}\text { hem. } \\
\text { (hem.) }\end{array}$ & $\begin{array}{c}\text { hem. + aka. } \\
-\end{array}$ & $\begin{array}{c}\text { hem. + aka./lep. } \\
\text { hem. + mag. + goe. + aka./lep. }\end{array}$ \\
\hline $\begin{array}{l}\text { M18/1-int } \\
\text { M24/1-upp } \\
\text { M24/1-low }\end{array}$ & $\begin{array}{l}\text { mag. + goe. + lep. } \\
\text { mag. + goe. + lep. } \\
\text { mag. + goe. + lep. }\end{array}$ & mag. & $\begin{array}{l}\text { mag. + goe. + lep. + aka. } \\
\text { mag. + goe. + lep. } \\
\text { mag. + goe. + lep. + aka. }\end{array}$ & mag. + goe. + aka./lep. \\
\hline
\end{tabular}

Further, the clusters of goethite can be influenced from surrounding clusters of material with different symmetry and magnetic properties (i.e., different phases present in the sample) affecting the hyperfine parameters and widening the distribution of the magnetic hyperfine field. In order to take these factors into account, the fitting of the presumably existing goethite component was performed here in a manner described in the Materials and Methods with the assumption of a Gaussian distribution of hyperfine fields $B_{\mathrm{hf}}$ being not larger than $15 \mathrm{~T}$. As Figure 13(b) makes clear, this resulted in markedly broadened linewidths, whereby the external lines of the sextet merge with the middle ones.

For the integral CP of M18/1, as displayed in Figure 13(c) and Table 3, a high portion of magnetite was found. Thus, this result addresses the aspect of an intake influence again. Further, a ferromagnetic fraction likely originates from goethite with a broad linewidth, as it was discussed above.

3.4.5. Summarising Considerations of Phase Analyses. The analytical findings for the CPs studied are compiled in Table 4. Summarising, there is a good agreement of the four analytical techniques applied. Incomplete agreements, e.g., in view of the presence of the single oxide hydroxides, may be tolerable because of the probable lateral heterogeneity in context with punctual sampling. After all, Fe(III) oxide hydroxide phases appear to play an important role in the composition of the formed CPs. Thermodynamically, it can be easily shown that the formation of $\alpha$-FeOOH from metallic iron and water is possible under aerobic conditions. From the tabulated data [40], a Gibbs free energy of reaction $\Delta_{\mathrm{r}} G^{\mathrm{o}}$ of $-357 \mathrm{~kJ} / \mathrm{mol}$ is calculated for $373 \mathrm{~K}$, the measured temperature level for the investigation sites in the preheater. The formation of $\beta$ - and $\gamma$-FeOOH needs the presence of chloride as a necessary or favourable prerequisite [18], which is fulfilled under the current conditions. In view of the thermal stability of goethite and the other $\mathrm{FeOOH}$ modifications, another thermodynamic calculation shows that the decomposition to the water-free oxide $\alpha-\mathrm{Fe}_{2} \mathrm{O}_{3}$ under release of water proves to be principally possible $\left(\Delta_{\mathrm{r}} G^{\mathrm{o}}=-3.5 \mathrm{~kJ} / \mathrm{mol}\right.$ for $\left.373 \mathrm{~K}\right)$. In reality, the $\mathrm{FeOOH}$ compounds are, however, sufficiently stable on the temperature level of about $100^{\circ} \mathrm{C}$.

This matter of fact could be unequivocally stated by DSC experiments with goethite and lepidocrocite, where the decomposition occurred indeed well beyond $250^{\circ} \mathrm{C}$ (Figure 14 for goethite). This observation is in agreement with literature data of Weckler and Lutz [24]. They stated 


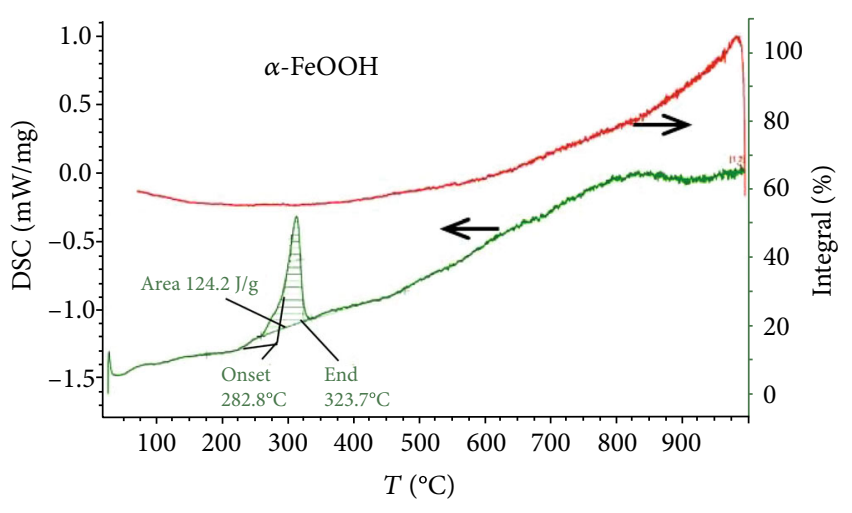

FIGURE 14: DSC tracks for goethite with decomposition to hematite, which was confirmed by the Raman spectroscopy. In case of lepidocrocite as starting product, maghemite $\left(\gamma-\mathrm{Fe}_{2} \mathrm{O}_{3}\right)$ was primarily formed.

a much faster decomposition rate of akaganeite than those of the other polymorphs, obviously due to the $\mathrm{Cl}^{-}$ion impurities present in this compound.

Thus, it can be emphasised for a relatively wide temperature range that the $\mathrm{FeOOH}$ species are metastable compounds whose decomposition is, obviously, kinetically hampered. This in turn can be considered a verification of our experimental findings that the $\mathrm{FeOOH}$ species represent significant components of the corrosion products formed under the relevant preheater conditions.

Further, it should be noted that thermodynamics claim for the presence of metallic iron as substrate that magnetite $\mathrm{Fe}_{3} \mathrm{O}_{4}$ containing $\mathrm{Fe}(\mathrm{II})$ aside from $\mathrm{Fe}(\mathrm{III})$ must be present in the contact zone to the metal, because $\alpha-\mathrm{Fe}_{2} \mathrm{O}_{3}$ will be reduced to $\mathrm{Fe}_{3} \mathrm{O}_{4}\left(\Delta_{\mathrm{r}} G^{\mathrm{o}}=-25.3 \mathrm{~kJ} / \mathrm{mol} \mathrm{Fe}_{3} \mathrm{O}_{4}, 373 \mathrm{~K}\right)$. Indeed, this phase was preferentially found for the lowoxygen conditions of intake 1 according to the infrared and Raman spectroscopy, XRD, and MS (Figures 10, 11, 12(b), and 13(c), Tables 2 and 3). Moreover, the evidence of magnetite was suggested by Mö $\beta$ bauer spectroscopy also for the lower, adherent fraction of CP layers formed under the conditions of intake 2 (Figure 13(b), Tables 2 and 3).

3.5. Chemical Contamination. Information on the occurrence of chemical species, which will influence the corrosion phenomena at the examination site, was gained from the water-based extraction of the coverings on the glassy conductivity sensors after an exposure period of 11 months.

Figure 9 shows analytical data for selected metal ion and anionic species determined for the inner surfaces of the both intakes. It is seen at a glance that there is a marked difference between the concentrations of corrosion relevant anionic species for both intakes. This means in view of the halogenides that especially intake 2 is characterised not only by a higher degree of "contamination," but also by more serious corrosive conditions. The findings may be interpreted by an unequal distribution of the chemical freights, which are transported in the mass streams from the rotary kiln into the both intakes including the chemically multifaceted input from the secondary fuel (Figure 15). Intake 2 is located on that side of the rotary kiln, where the upward motion takes

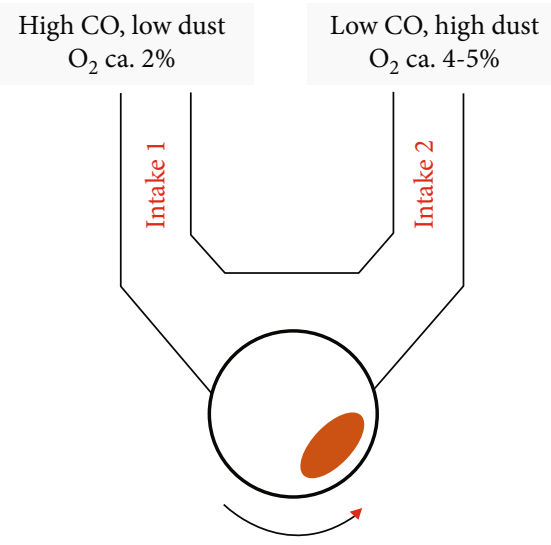

FIGURE 15: Different mass transport in both intakes of the preheater.

TABle 5: Open circuit potentials (mean values at $200 \mathrm{~s}$ after immersion start of three measurements each) for $1 \mathrm{M} \mathrm{KCl}$ electrolyte solution.

\begin{tabular}{lc}
\hline Condition & ocp $(\mathrm{mV})$ \\
\hline Ambient temp., aerated, unstirred & -610 \\
$40{ }^{\circ} \mathrm{C}$, aerated, unstirred & -637 \\
Ambient temp., pressurised-air purge & -530 \\
Ambient temp., $\mathrm{N}_{2}$ purge & -599 \\
\hline
\end{tabular}

places, so that a greater part of dusty particles are forwarded into this branch. Contrarily, intake 1 is fed with the greater portion of combustion gases, among those also carbon monoxide CO. Gas analyses carried out separately make clear that intake 2 has a higher oxygen concentration than intake 1 with a typical oxygen difference of $2-3 \%$. These facts are responsible that also the corrosion phenomena, as discussed above, are substantially different, with the mild steel exposed in intake 2 undergoing a markedly higher corrosion rate and a more distinct CP formation.

3.6. Electrochemical Lab Investigations. The following electrochemical investigations were done to clear up the importance of oxygen and chloride content in the exhaust air of the two intakes. Therefore, the parameters for the model electrolyte solutions were varied correspondingly. Open circuit potentials (Table 5) are given for different aeration and temperature conditions based on measurements in $1 \mathrm{M} \mathrm{KCl}$ solution. Parallel measurements showed ocp differences of a few $\mathrm{mV}$ only; also, the temporal movements over $10 \mathrm{~min}$ were small. The ocp for enhanced temperature under aerated, but unstirred conditions, occupies the most negative position. The considerable positive ocp shift under forced aeration through pressurised air is in accordance with the mixed potential theory. Similar findings in view of aeration/ deaeration were gained, e.g., for carbon steel in a nearneutral mixed carbonate-chloride-sulphate salt medium under consecutively varied gas purging regimes [41, 42].

Figure 16 depicts the influence of different aeration on the course of voltammetric measurements and the Stern- 


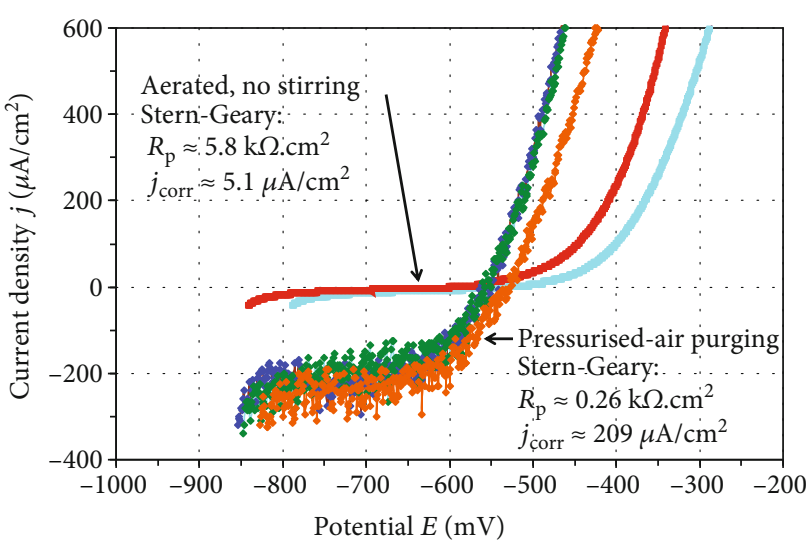

FIGURE 16: Single polarisation measurements under varied aeration conditions at ambient temperature recorded after $0.5-1 \mathrm{~h}$ of immersion in $0.1 \mathrm{M} \mathrm{KCl}$ electrolyte solution from cathodic $($ ocp $-0.3 \mathrm{~V})$ to anodic with $1 \mathrm{mV} / \mathrm{s}$; inserts: corresponding SternGeary corrosion data (mean values).

Geary corrosion data as well. Under pressurised-air purging, the ocp is shifted in the positive direction, and the cathodic currents are favoured in accordance with the mixed potential theory. The control of the corrosion rate at ocp is more on the side of the cathodic partial reaction, because the oxygen reduction takes place under a high degree of transport control, where the diffusion layer thickness is substantially decreased for the vigorously moved electrolyte solution. It is easily conceivable that the corresponding curves are subject of higher scattering due to the less controlled air purging. The outlined situation is reflected also by the mean values of the polarisation resistance $R_{\mathrm{p}}$ and the corrosion current density $j_{\text {corr }}$, which surpass for pressurised-air conditions those for the unstirred state by a factor of about 40 (Figure 16, inserts).

After all, the major role of oxygen/cathodic partial reaction for the corrosion process is emphasised, thus confirming the derived statements for the real corrosion phenomena encountered at the examination site of the preheater.

A recalculation of the corrosion current density $j_{\text {corr }}$ into a corrosion rate based on the thickness loss of steel $k_{\mathrm{d}}$ gives, according to Equation (3), a corrosion rate of $k_{\mathrm{d}}=58 \mu \mathrm{m} / \mathrm{a}$ $\left(j_{\text {corr }}=5 \mu \mathrm{A} / \mathrm{cm}^{2}\right)$. This roughly conforms to the order of magnitude of the values of Table 1 , which was measured for the preheater-exposed steel plates. $M_{\mathrm{Fe}}$ : atomic mass of Fe $(55.85 \mathrm{~g} / \mathrm{mol}) ; z$ : charge-transfer number for the dissolution reaction (2); F: Faraday's number $\left(9.65 \times 10^{4} \mathrm{As} / \mathrm{mol}\right) ; \rho_{\mathrm{Fe}}$ : density $\left(7.85 \mathrm{~g} / \mathrm{cm}^{3}\right)$.

$$
k_{d}=\frac{j_{\mathrm{corr}} \cdot M_{\mathrm{Fe}}}{z \cdot F \cdot \rho_{\mathrm{Fe}}} .
$$

In addition to the dc measurements, ac perturbation was applied to gain a deeper insight into mechanistic issues. The Bode diagram of Figure 17 illustrates the impedance behaviour in $1 \mathrm{M} \mathrm{KCl}$ solutions in terms of the influence of aeration, deaeration through simultaneous $\mathrm{N}_{2}$ purging, and temperature enhancement to $40^{\circ} \mathrm{C}$. The depicted curves, chosen from a series of consecutive EIS measurements over $5 \mathrm{~d}$

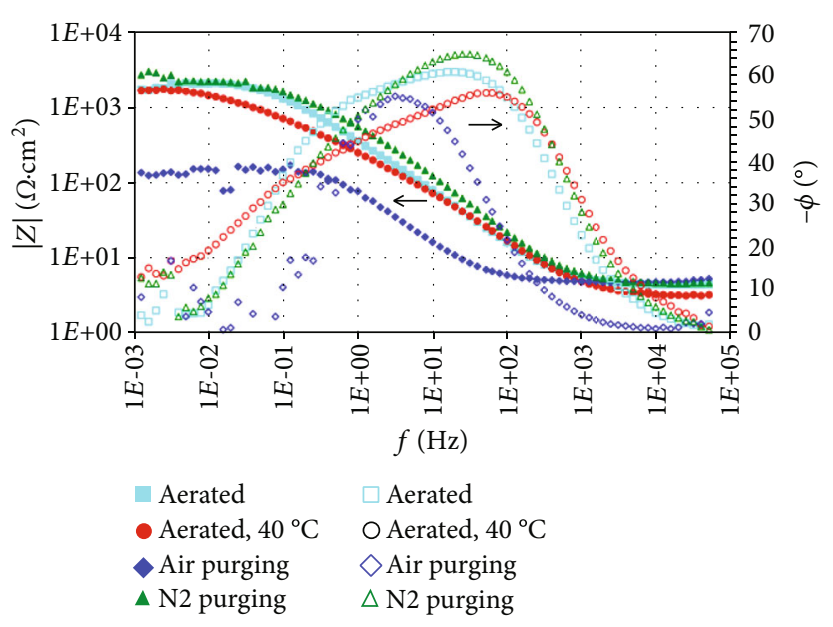

Figure 17: EIS measurements (Bode plot) under varied aeration/deaeration and temperature conditions recorded after $3 \mathrm{~h}$ of immersion in $1 \mathrm{M} \mathrm{KCl}$ electrolyte solution at ocp.

each, refer to a resting time of $3 \mathrm{~h}$ in order to provide for approximate stationarity during the longer-lasting EIS measurement. On the other hand, significant covering by corrosion products, i.e., the development of an inhomogeneous surface, which had been previously taken into account by different authors $[43,44]$, should be avoided. Here, the thickness of the formed CP layer could be estimated to $5 \times 10^{-8} \mathrm{~m}$ for unstirred conditions, based on the corrosion current density of $5 \mu \mathrm{A} / \mathrm{cm}^{2}$ (cf. Figure 16).

Irrespective of quantitative differences between the three curve pairs for aerated, aerated $/ 40^{\circ} \mathrm{C}$, and deaerated conditions, they show a nonidentical shape. The curves are characterised by a number of features: (i) the asymmetric shape of the phase angle bumps at medium frequencies, (ii) the flattening slope of $\log |Z|$ in the direction of decreasing frequency, and (iii) the low-frequency (LF) plateau of about $2 \mathrm{k} \Omega \mathrm{cm}^{2}$. It is somewhat surprising that the LF $\log |Z|$ values for these condition sets differ only negligibly. As for the enhanced temperature, it may be argued that the expected reactivity increase will be counteracted by the decreased oxygen solubility. The curves for simultaneous air purging show, notwithstanding the scatter, a more symmetric shape of the phase angle course associated with a considerably decreased LF $\log |Z|$ plateau of about $0.15 \mathrm{k} \Omega \mathrm{cm}^{2}$ . This is a further evidence for the decisive role of oxygen for the corrosion. Finally, the LF plateau levels confirm the behaviour at dc (Figure 16) very well.

The high-frequency (HF) plateau of $\log |Z|$ at the righthand side of the spectra allows reading the electrolyte resistance $R_{\mathrm{e}}$, which is, of course, dependent both on the electrolyte concentration and on the temperature. Indeed, three of the condition sets show completely coinciding electrolyte resistances of about $4 \Omega \mathrm{cm}^{2}$, whilst $R_{\mathrm{e}}\left(40^{\circ} \mathrm{C}\right)$ is somewhat lower in accordance with theory.

Modelling of the measured curves was best performed using a modified Randles equivalent circuit (Figure 18(a)). It contains two features: (i) a constant phase element (CPE) with the parameters $T(\mathrm{CPE})$ and $P(\mathrm{CPE})$ instead of the pure 


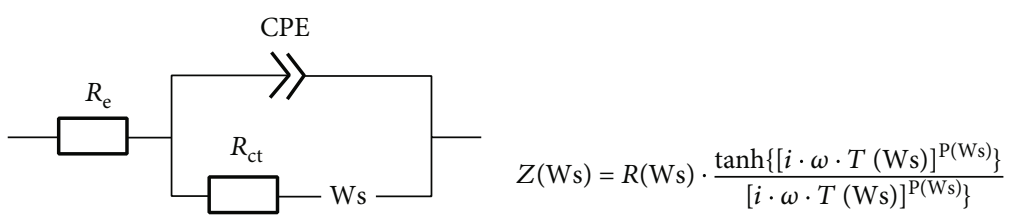

(a)

(b)
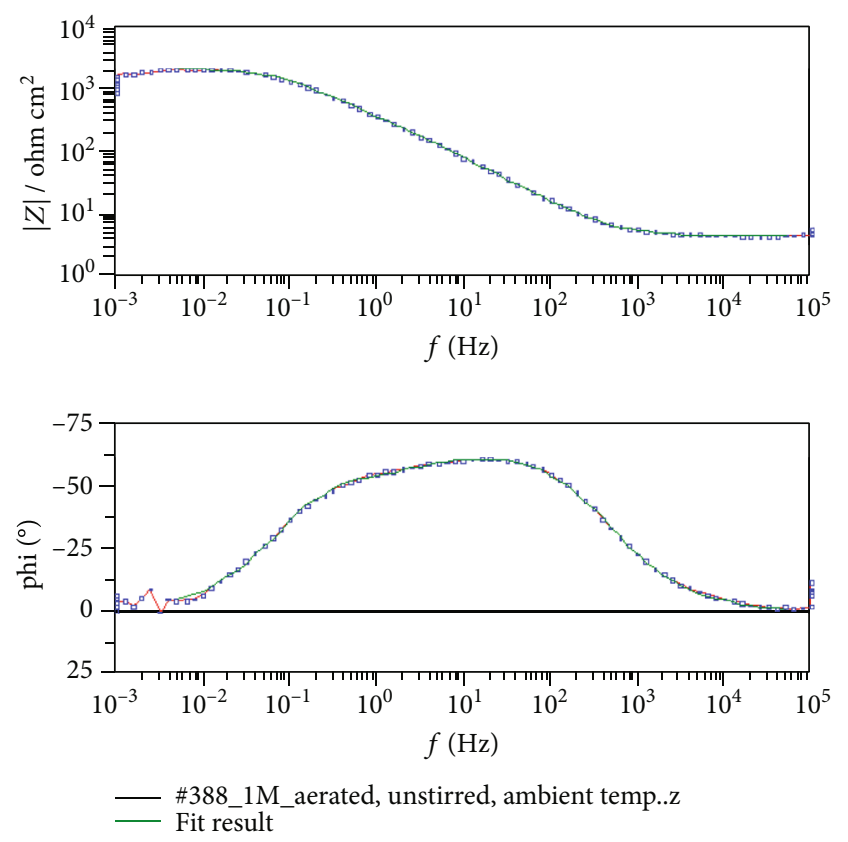

\begin{tabular}{|c|c|c|c|}
\hline Element & Freedom & Value & Error \% \\
\hline$R_{e}$ & \pm Free $(t)$ & 4,298 & 0,30468 \\
\hline $\boldsymbol{R}_{\mathrm{ct}}$ & \pm Free $(t)$ & 118 & 36,288 \\
\hline$R(\mathrm{Ws})$ & \pm Free $(+)$ & 2076 & 2,101 \\
\hline$T(W s)$ & \pm Free $(+)$ & 2,649 & 6,9366 \\
\hline$P(\mathrm{Ws})$ & \pm Free $(+)$ & 0,41674 & 1,1583 \\
\hline$T(\mathrm{CPE})$ & \pm Free $(t)$ & 0,00038474 & 5,353 \\
\hline$P(C P E)$ & \pm Free $(+)$ & 0,80684 & 0,78867 \\
\hline
\end{tabular}

(c)

(d)

Figure 18: (a) Randles-based equivalent circuit. $R_{\mathrm{e}}$ : electrolytic resistance; $R_{\mathrm{ct}}$ : charge-transfer resistance; CPE: constant phase element; Ws: modified Warburg impedance with finite diffusion length. (b) Impedance equation for Ws provided with the parameters $R(\mathrm{Ws}), T(\mathrm{Ws})$, and $P($ Ws $)$ acc. to ZView; $i$ imaginary unit; $\omega$ : angular frequency. (c) Measured and fitted curves for $1 \mathrm{M} \mathrm{KCl}$, ambient temperature, aerated, and unstirred conditions. The lowest frequency points were omitted due to scattering. (d) Corresponding fitted parameters.

double layer capacity and (ii) an element Ws designed for a finite diffusion length $d$, which is characterised by a finite limiting value of its real part for $f=0$, instead of the original Warburg diffusion impedance [45]. The corresponding impedance equation for Ws is inserted in Figure 18(b). It can be shown that the ZView-based parameter $R(\mathrm{Ws})$ is equal to the limiting value mentioned above. Parameter $T$ (Ws) stands for $d^{2} / D$, where $D$ is the diffusion coefficient for dissolved oxygen $\left(2.1 \times 10^{-5} \mathrm{~cm}^{2} / \mathrm{s}\right.$ at $\left.298 \mathrm{~K}\right)$ and $d$ is the diffusion length. Finally, parameter $P(\mathrm{Ws})$ is nearby 0.5 .

The selected measurement for aerated, unstirred conditions documents the high goodness of fitting (Figure 18(c)). As the figures of the table in Figure 18(d) point out, the diffusion-related resistance $R$ (Ws) is determined to be more than one order larger than the interface-related resistance $R_{\mathrm{ct}}$. That means diffusion plays a significant role within the total process and forms the rate-determining step. Thus, diffusion control is active both for the cathodic reduction (as was evidenced by dc measurements, cf. Figure 16) and for normal corrosion at ocp.

Turning to air purging, the parameter $R(\mathrm{Ws})$ is dramatically reduced down to $0.15-0.2 \mathrm{k} \Omega \mathrm{cm}^{2}$ in agreement with the decreased level of the measured $\operatorname{LF} \log |Z|$ pla- teau in Figure 17. It appears now that the inverse relation $R$ (Ws) $<R_{\text {ct }}$ holds, which conforms to the improved diffusion under convective conditions.

A second impedance diagram (Figure 19) addresses different solution compositions. These curves provide evidence that a concentration modification from 1 to $0.1 \mathrm{~mol} / \mathrm{L} \mathrm{KCl}$ does not give significant change in the LF $\log |Z|$ plateau. A similar result, within the normal scatter, is gained, when the chloride is completely removed using the sulphate salt of the same molar concentration. This means that the overall corrosion rate will not be essentially influenced by the actual concentration or even by the absence of chloride anions. The negligible chloride influence may be regarded as unexpected, because it is well known that the chloride ion is involved in the anodic dissolution mechanism [46]. However, earlier experiments using AISI 4340 low-alloyed steel in neutral sulphate and chloride solutions [47] gave similar results. Further, a relatively low concentration dependence of corrosion current densities was observed in polarisation measurements on SAE 1010 carbon steel in aerated $0.02-1 \mathrm{M} \mathrm{NaCl}$ solutions $[44,48]$. This was explained by the fact that both partial reactions-the cathodic partial reaction with mixed control of charge-transfer and mass transport and the anodic 


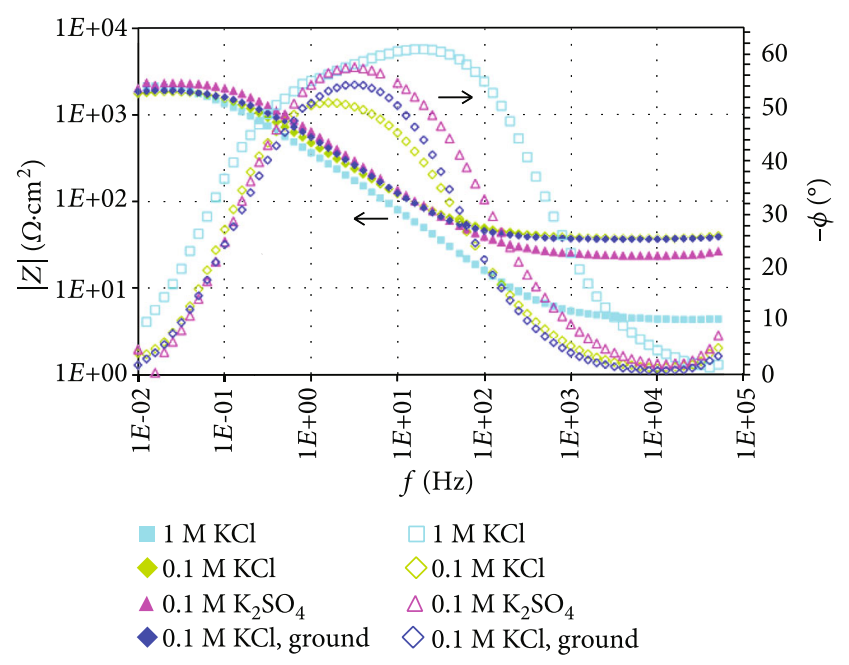

FIGURE 19: EIS measurements (Bode plot) recorded after $3 \mathrm{~h}$ of immersion in different electrolyte solutions at ocp under ambient temperature and aeration without stirring; comparative application of wet-ground surface.

subprocess with pure charge-transfer control-undergo a concentration influence.

As for the electrolyte resistance, the ratios of the $R_{\mathrm{e}}$ values for $R_{\mathrm{e}}(0.1 \mathrm{MKCl}) / R_{\mathrm{e}}(1 \mathrm{MKCl})=8.3$ and for $R_{\mathrm{e}}(0.1 \mathrm{MKCl}) /$ $R_{\mathrm{e}}\left(0.1 \mathrm{MK}_{2} \mathrm{SO}_{4}\right)=1.58$ reflect the specific effects of the involved ions quite regularly. Theory states that the electrolytic conductivity and, hence, the reciprocal of the electrolyte resistance are determined by the product of ionic charge, ionic concentration, and ionic mobility [49].

Finally, a few EIS measurements referred to the influence of the surface pretreatment. As the forth curve pair in Figure 19 evidences, wet-grinding, i.e., removing the rolling skin, led practically to no differing results.

\section{Conclusions}

Unlike earlier investigations that were directed to the events in the rotary kiln region, this study focused on the corrosion and the underlying conditions in the zone of the preheater of a running cement clinker production facility, more precisely at the inner surface of the mild steel preheater cladding. The following conclusions are drawn from the exposure experiments performed over a long-term period of 24 months as well as from the lab investigations:

(i) It was possible to record humidity and temperature on-line during the production process by inserting special sensors directly at the specific preheater sites that were relevant for the corrosion investigation. The temperature movements following onset and shut-down of operation were found to be associated with in-phase movements of the relative humidity. This was attributed to the participation of the built-in ceramic materials as water sorbents/desorbents. An unambiguous evidence of liquid water at the inner surface of the cladding could not be found (ii) The corrosion phenomena at the inner surface of the preheater mantle were tracked by reexposure of four large-area, indigenous steel plate cutouts of the mantle. The two parallel intakes 1 and 2 were taken into account. Generally, the steel corrosion was affected by contaminants, originating from secondary fuels. Appearance and structure of the corrosion products were found to be not mainly dependent on the varied length of exposure, as was expected in the beginning. Instead, it became apparent that the preheater branch exerts the major influence. The plates in the preheater branch that are influenced by the higher oxygen and chloride concentrations (intake 2) show a markedly higher corrosion rate and, correspondingly, corrosion product (CP) layers of higher thickness. In addition, a distinct spalling character of the upper portions of these CPs was observed

(iii) The investigations made a contribution to a safer operation of the whole production facility as well as to the maintenance procedures

(iv) Various independent analytic methods for the identification of the present oxidic phases yielded a vast agreement. Whilst hematite proved the main component of the CPs formed in intake 2 under conditions of higher oxygen concentrations, magnetite was identified for low-oxygen conditions (intake 1). Different Fe(III)-oxyhydroxide phases were identified by the multianalytical approach. These substances play an important role in the composition of the CPs formed, though being a basically metastable compound class. For the factory-assigned position of examination in the preheater zone was stated that a corrosion process takes place under conditions of humidity, limited oxygen access, and chloride ion presence at an elevated temperature level of about $100-110^{\circ} \mathrm{C}$. A typical high-temperature corrosion mechanism could be distinctly excluded

(v) The electrochemical laboratory investigations emphasised the presence of oxygen as a key factor in the occurring corrosion of the unalloyed steel. It was proved by linear polarisation and impedance measurements that diffusion control dominates both for the cathodic reduction and for normal corrosion without polarisation. A roughly coincident level of the corrosion current density was determined by the both methodical approaches (dc/ac). Further, a satisfactory agreement could be established between the electrochemical lab data for the corrosion rate and the metallographically determined data after real preheater exposure

(vi) An accelerating effect of chloride ions could not be derived for the investigated laboratory model conditions. This may be explained by the markedly simplifying conditions compared with the high in-plant complexity. Nevertheless, further need of research at temperatures close to the real data is seen. 


\section{Data Availability}

The data used to support the findings of this study are included within this article and parts of the voluminous raw/processed data required to reproduce these findings can be shared on demand by the corresponding author.

\section{Conflicts of Interest}

The authors declare that there is no conflict of interest with any individual/organisation for the present work.

\section{Acknowledgments}

This research was funded by the Bundesministerium für Bildung und Forschung/Projektträger Jülich under contract no. 03X3590G. The open access publication is funded by the Publication Fund of the TU Dresden. The authors express their gratitude to Dr.-Ing. Hans-Jürgen Schneider (CALSITHERM Silikatbaustoffe GmbH, Paderborn) for fruitful discussion and support. The authors are much obliged to Dipl.-Phys. Axel Mensch (Dresden University of Technology; SEM-EDX) and Prof. Dr. Jörg Feller (University of Applied Sciences Dresden; XRD, ICP-OES, IC). Special thanks go to Dr. Helfried Reuther for his support in the analysis of Mö $\beta$ bauer spectra. Further, the authors are indebted to Katja Galle, Julia Tondera, Gero Wiemann (all at Dresden University of Technology), and Matthias Ringsleben (OPTERRA Zement GmbH, Plant Karsdorf) for different technical service.

\section{References}

[1] M. B. Ali, R. Saidur, and M. S. Hossain, "A review on emission analysis in cement industries," Renewable and Sustainable Energy Reviews, vol. 15, no. 5, pp. 2252-2261, 2011.

[2] E. Benhelal, G. Zahedi, E. Shamsaei, and A. Bahadori, "Global strategies and potentials to curb $\mathrm{CO} 2$ emissions in cement industry," Journal of Cleaner Production, vol. 51, pp. 142161, 2013.

[3] S. P. Deolalkar, "Alternative Fuels and Raw Materials," in Designing Green Cement Plants, pp. 63-136, Elsevier, Amsterdam, 2015.

[4] S. Lechtenböhmer et al., Einsatz von Sekundärbrennstoffen, Forschungsbericht, Dessau, 2006 , https://www .umweltbundesamt.de.

[5] M. Huang, X. Ying, D. Shen et al., "Evaluation of oil sludge as an alternative fuel in the production of Portland cement clinker," Construction and Building Materials, vol. 152, pp. 226231, 2017.

[6] B. Nakomcic-Smaragdakis, Z. Cepic, N. Senk, J. Doric, and L. Radovanovic, "Use of scrap tires in cement production and their impact on nitrogen and sulfur oxides emissions," Energy Sources, Part A: Recovery, Utilization, and Environmental Effects, vol. 38, no. 4, pp. 485-493, 2016.

[7] J. Rovira, M. Mari, M. Nadal, M. Schuhmacher, and J. L. Domingo, "Use of sewage sludge as secondary fuel in a cement plant: human health risks," Environment International, vol. 37, no. 1, pp. 105-111, 2011.
[8] E. Kötter and P. Bartha, "Untersuchungen zum Problem der Ofenmantelkorrosion," in Proc. Refra Kolloquium '86, S, pp. 104-123.

[9] A. K. Chatterjee, "Role of Volatiles in Cement Manufacture and in the Use of Cement," in Advances in Cement Technology, S. N. Ghosh, Ed., p. 203, Elsevier, Amsterdam, 1983.

[10] M. Filippich and D. Laschek, Alkali-, Schwefel- und Chlorkreisläufe im Zementofen, Refratechnik-Bericht Nr, Göttingen, 2005.

[11] A. S. Khanna, High temperature corrosion, World Scientific, Singapore, 2016.

[12] M. Mäkipää, P. Makkonen, and R. J. Fordham, "Modeling of low-temperature oxidation of steel tubes in biomass combustion," Materials Science Forum, vol. 461-464, pp. 999-1006, 2004.

[13] K. Weulersse, G. Moulin, P. Billard, and G. Pierotti, "High temperature corrosion of superheater tubes in waste incinerators and coal-fired plants," Materials Science Forum, vol. 461464, pp. 973-980, 2004.

[14] T. Herzog, W. Spiegel, and W. Müller, "Corrosion as a Result of Dew Points and Deliquescent Salts in the Boiler and the Flue Gas Treatment System," in Waste Management, K. J. ThoméKozmiensky and S. Thiel, Eds., vol. 3, pp. 343-358, TK Verlag, Neuruppin, 2012.

[15] L. Krumm and M. C. Galetz, "Chlorine attack of carbon steel between 350 and $500{ }^{\circ} \mathrm{C}$ and its importance regarding corrosion in waste incineration," Oxidation of Metals, vol. 87, no. 5-6, pp. 757-766, 2017.

[16] N. Brachhold, S. Schafföner, and C. G. Aneziris, "Investigation of alkali corrosion resistance of potassium aluminosilicates using statistical techniques," Ceramics International, vol. 41, no. 1, pp. 1447-1456, 2015.

[17] D. G. Rancourt and J. Y. Ping, "Voigt-based methods for arbitrary-shape static hyperfine parameter distributions in Mössbauer spectroscopy," Nuclear Instruments and Methods in Physics Research Section B: Beam Interactions with Materials and Atoms, vol. 58, no. 1, pp. 85-97, 1991.

[18] U. Schwertmann and R. M. Cornell, Iron Oxides in the Laboratory - Preparation and Characterization, Wiley-VCH, Weinheim, 2000.

[19] "Reference Electrode Potentials," 2018, https://www.edaq .com/wiki/Reference_Electrode_Potentials.

[20] F. Mansfeld and K. B. Oldham, "A modification of the SternGeary linear polarization equation," Corrosion Science, vol. 11, no. 10, pp. 787-796, 1971.

[21] W. Strunz, "Appearance and reality in impedance spectroscopy - detection and prevention of artefacts in impedance measurements," in Proc. of Kronach Impedance Days 2009 "Hermann Göhr".

[22] “Standardfehler," 2019, https://matheguru.com/stochastik/ standardfehler.html.

[23] R. Antunes, R. U. Ichikawa, L. G. Martinez, and I. Costa, "Characterization of corrosion products on carbon steel exposed to natural weathering and to accelerated corrosion tests," International Journal of Corrosion, vol. 2014, Article ID 419570, 9 pages, 2014.

[24] B. Weckler and H. D. Lutz, "Lattice vibration spectra. Part $\mathrm{XCV}$. Infrared spectroscopic studies on the iron oxide hydroxides goethite $(\alpha)$, akaganéite $(\beta)$, lepidocrocite $(\gamma)$, and feroxyhite $(\delta)$," European Journal of Solid State and Inorganic Chemistry, vol. 35, no. 8-9, pp. 531-544, 1998. 
[25] W. Cai and J. Wan, "Facile synthesis of superparamagnetic magnetite nanoparticles in liquid polyols," Journal of Colloid and Interface Science, vol. 305, no. 2, pp. 366-370, 2007.

[26] L. Ying-Sing, J. S. Church, and A. L. Woodhead, "Infrared and Raman spectroscopic studies on iron oxide magnetic nanoparticles and their surface modifications," Journal of Magnetism and Magnetic Materials, vol. 324, pp. 1543-1550, 2012.

[27] T. Misawa, M. Yamashita, Y. Matsuda, H. Miyuki, and H. Nagano, "Protective rust layer formed on weathering steel by atmospheric corrosion for a quarter of a century," Tetsuto-Hagane, vol. 79, no. 1, pp. 69-75, 1993.

[28] M. Gotić and S. Musić, "Mössbauer, FT-IR and FE SEM investigation of iron oxides precipitated from $\mathrm{FeSO}_{4}$ solutions," Journal of Molecular Structure, vol. 834-836, pp. 445-453, 2007.

[29] I. C. G. Thanos, "In situ Raman and other studies of electrochemically oxidized iron-9\% chromium alloy," Electrochimica Acta, vol. 31, no. 7, pp. 811-820, 1986.

[30] L. Bellot-Gurlet, D. Neff, S. Réguer, J. Monnier, M. Saheb, and P. Dillmann, "Raman studies of corrosion layers formed on archaeological irons in various media," Journal of Nano Research, vol. 8, pp. 147-156, 2009.

[31] S. Li and L. H. Hihara, "In situ Raman spectroscopic identification of rust formation in Evans' droplet experiments," Electrochemistry Communications, vol. 18, pp. 48-50, 2012.

[32] A. L. Mackay, “ $\beta$-ferric oxyhydroxide," Mineralogical Magazine and Journal of the Mineralogical Society, vol. 32, no. 250, pp. 545-557, 1960.

[33] A. L. Mackay, " $\beta$-ferric oxyhydroxide-akaganéite," Mineralogical Magazine and Journal of the Mineralogical Society, vol. 33, no. 259, pp. 270-280, 1962.

[34] T. Peev, V. Taseva, and A. Akala, "Aufklärung von Korrosionsprozessen bei der Erdölverarbeitung mittels Mössbauer- und Röntgenuntersuchung - II. Wasserkondensator und Separatoren," Werkstoffe und Korrosion, vol. 44, no. 2, pp. 62-65, 1993.

[35] Y. R. Uhm, W. W. Kim, and C. K. Rhee, "Phase control and Mössbauer spectra of nano $-\mathrm{Fe}_{2} \mathrm{O}_{3}$ particles synthesized by the levitational gas condensation (LGC) method," Physica Status Solidi (a), vol. 201, no. 8, pp. 1934-1937, 2004.

[36] K. E. García, C. A. Barrero, A. L. Morales, and J.-M. Greneche, Magnetic structure of synthetic akaganeite: a review of Mössbauer data, Rev. fac. ing. univ., Antioquia no. 49 Medellín, 2009, http://www.scielo.org.co/scielo.php?script=sci_ arttext\&pid=S0120-62302009000300018.

[37] R. E. Vandenberghe and E. De Grave, "Application of Mössbauer spectroscopy in earth sciences," in Mössbauer Spectroscopy - Tutorial Book, Y. Yoshida and G. Langouche, Eds., pp. 91-185, Springer, 2013.

[38] E. Murad, "The characterization of goethite by Mössbauer spectroscopy," American Mineralogist, vol. 67, pp. 10071111, 1982.

[39] C. van der Zee, C. P. Slomp, D. G. Rancourt, G. J. De Lange, and W. van Raaphorst, "A Mössbauer spectroscopic study of the iron redox transition in eastern Mediterranean sediments," Geochimica et Cosmochimica Acta, vol. 69, pp. 441-453, 2005.

[40] O. Knacke, O. Kubaschewski, and K. Hesselmann, Eds., Thermochemical Properties of Inorganic Substances, Springer, Berlin, 1991.

[41] B. W. A. Sherar, P. G. Keech, and D. W. Shoesmith, "Carbon steel corrosion under anaerobic-aerobic cycling conditions in near-neutral $\mathrm{pH}$ saline solutions. Part 1: Long term corrosion behaviour," Corrosion Science, vol. 53, pp. 3636-3642, 2011.

[42] B. W. A. Sherar, P. G. Keech, and D. W. Shoesmith, "Carbon steel corrosion under anaerobic-aerobic cycling conditions in near-neutral $\mathrm{pH}$ saline solutions. Part 2: Corrosion mechanism," Corrosion Science, vol. 53, pp. 3643-3650, 2011.

[43] K. Jüttner, W. J. Lorenz, M. W. Kendig, and F. Mansfeld, "Electrochemical impedance spectroscopy on 3-D inhomogeneous surfaces," Journal of the Electrochemical Society, vol. 135, pp. 332-339, 1988.

[44] L. Cáceres, T. Vargas, and L. Herrera, "Influence of pitting and iron oxide formation during corrosion of carbon steel in unbuffered $\mathrm{NaCl}$ solutions," Corrosion Science, vol. 51, pp. 971-978, 2009.

[45] J. L. Dawson and D. G. John, "Diffusion impedance - an extended general analysis," Journal of Electroanalytical Chemistry and Interfacial Electrochemistry, vol. 110, no. 1-3, pp. 3747, 1980.

[46] K.-H. Tostmann, Korrosion - Ursachen und Vermeidung, Weinheim, Wiley-VCH, 2001.

[47] F. Mansfeld, M. W. Kendig, and W. J. Lorenz, "Corrosion inhibition in neutral, aerated media," Journal of the Electrochemical Society, vol. 132, no. 2, pp. 290-296, 1985.

[48] L. Cáceres, T. Vargas, and L. Herrera, "Determination of electrochemical parameters and corrosion rate for carbon steel in un-buffered sodium chloride solutions using a superposition model," Corrosion Science, vol. 49, no. 8, pp. 3168-3184, 2007.

[49] “Ionic Mobility Tables," 2018, http://medicalsciences.med .unsw.edu.au/research/research-services/ies/ ionicmobilitytables. 